

\section{SPECTROSCOPIC AND OPTICAL STUDIES OF A HIGH PRESSURE, UNDEREXPANDED JET}

Stuart W. Bowen, Assistant Research Engineer Department of Aerospace Engineering

The University of Michigan, Ann Arbor, Michigan

\section{ABSTR ACT}

Argon heated to $5000^{\circ} \mathrm{K}$ at 10 atmospheres in a DC arc plasma generator was expanded through a sonic orifice into the atmosphere, forming a selfluminous jet with the characteristic underexpanded structure.

The plasma generator and its performance are discussed and luminosity profiles across the jet are given. Physical conditions determined by optical spectroscopy in the jet were investigated.

The affects of adding small amounts of $\mathrm{H}_{2}$ and $\mathrm{N}_{2}$ to the argon are discussed.

Even though equilibration times between arc passage and nozzle exit were greater than $10^{-2} \mathrm{sec}$, LTE did not exist, the radiation from spectral lines being many orders of magnitude too large. A conjecture that resonance trapping of the argon ground state radiation may be the problem is briefly discussed.

\section{INTRODUCTION}

The analysis of the optical radiation from plasmas and its relation to the plasma properties has been a subject of wide spread attention for the last few years. The success of spectroscopic methods in plasmas having simple geometrical shapes such as the uniform slabs of radiating gas which occur in shock tubes and the axisymmetric configurations which occur in wall stabilized arcs suggest application to more complicated situations of practical interest.

The radiation from a plasma which has a complex hydrodynamic structure is an area which has not been thoroughly explored to date. Very little is known, either theoretically or experimentally, about the downstream flow structure in such a simple well defined case as when a plasma obeying the perfect gas law issues from a sonic orifice at high pressures to form an axisymmetric jet. To avoid unnecessary complications, the gas forming the plasma should be chosen to avoid chemical reactions and also be one for which thermodynamic and spectroscopic properties are known. It was felt that extreme purity of the gas was not necessary however so long as the gross hydrodynamic properties were not affected. An arc heated argon plasma appeared to satisfy most of these criterion.

The initial idea for this work was first to provide a high pressure, equilibrium argon plasma (the plasma is actually highly nonequilibrium) and then explore by spectroscopic and optical methods the downstream properties in the jet, inferring the temperatures and particle densities, and correlating these with the hydrodynamic features.

Most previous spatially resolved spectroscopic studies in plasma jets (1-5) have used correctly expanded or subsonic exit conditions at chamber pressures up to 2 atmospheres. The resulting temperature distributions smoothly decrease along the jet axis and radially outward much in the manner of a candle flame. 
Peters (6) was the first to describe and show pictures of the sort of highly underexpanded plasma jet that we are interested in here. He used a Gerdien type, water filled plasma generator obtaining $8000^{\circ} \mathrm{K}$ at 50 atmospheres, expanding through a converging-diverging nozzle which formed the anode. He noted the correlation of the luminous structure of the plasma jet with the hydrodynamic structure as shown in schlieren pictures and measured the Mach angle in the flow.

Watson et al. (7) made $\mathrm{N}_{2}$ rotational temperature measurements in a low pressure underexpanded argon jet expanding from $100 \mathrm{~mm}$ at $7100^{\circ} \mathrm{K}$ to $6 \mathrm{~mm}$ ambient pressure, and found the local temperature maxima were slightly downstream of the visual Mach diamonds.

In the following paper we shall review the structure of underexpanded jets, describe the equipment used to produce a self-luminous underexpanded argon jet and discuss its performance, review the formulas and methods used to interpret the spectral measurements in the jet and then discuss the results of these measurements with particular emphasis given to the nonequilibrium character of the radiation.

\section{UNDEREXPANDED JET STRUCTURE}

The hydrodynamic structure of an underexpanded (exit pressure higher than ambient pressure) jet is schematically shown in Fig. 1. Several features common to underexpanded jets are the Prandtl-Meyer expansion of the fluid at the nozzle lip down to ambient pressure along the jet boundary, the formation of an intercepting oblique shock which joins the outer edge of the normal shock called the Mach disk, which together enclose the shock free inner region known as the Mach bottle, the oblique reflected shock from the $-3-$
Mach disk which reflects from the jet boundary as an expansion fan and the subsequent Mach diamond structure of compressions and rarefactions which extends downstream. The Mach diamonds are regions of compression with expansion regions lying between. These successive compressions and rarefactions are due to the fact the gas has inertia and therefore over and underexpands while being carried along by the jet.

Note the slip line extending downstream from the triple shock at the outer edge of the Mach disk, across which the temperature and density are discontinuous, while pressure is continuous. That gas which passes through the two outer oblique shocks does not have the same thermodynamic state as the gas passing through the normal shock.

Figures $2 \mathrm{a}$ and $2 \mathrm{~b}$ are schlieren pictures of room temperature air at 7.5 atmospheres expanding through a sonic orifice to room conditions. Figure 2a has the knife edge perpendicular to the jet axis, and Fig. 2b has the knife edge parallel to the jet axis. Figure $2 c$ is a direct photograph of an underexpanded self-luminous argon jet expanding from 9.4 atmospheres and $5000^{\circ} \mathrm{K}$ to the atmosphere through a sonic orifice. The similarity of the luminosity and shock structure is clearly evident.

The structure of such jets has been extensively reviewed by Adamson (8), Adamson and Nicholls (9), and Love et al.(10).

Only limited theoretical studies of the jet structure and properties in the jet (see Ref. 9) have been possible because of great mathematical difficulties. The method of characteristics numerically predicts quite accurately the conditions an! geometry upstream of the Mach disk and reflected shock but 
fails completely to predict the existence of the Mach disk and subsequent downstream structure which consists of mixed supersonic and subsonic flow.

The position of the Mach disk is empirically determined to good accuracy by requiring the static pressure behind the Mach disk to be ambient (9).

A relation valid at low pressure ratios was given by Prandtl (11) for the spacing between the successive Mach diamonds.

Experimentally, Adamson and Nicholls (9), Love et al. (10), Wilcox et al. (12), and Crist et al. (13), have made extensive measurements on the location of the various features seen in Fig. 2 as a function of pressure ratio, specific heat ratio and nozzle exit Mach number.

Ladenburg et al. (14) measured the density in an underexpanded, atmospheric temperature jet of air expanding into room conditions, by means of the fringe shift in a Mach Zehnder interferometer. These measurements concentrated on the area between the nozzle and slightly downstream of the Mach disk. The agreement between Ladenburg's measurements and the characteristics solution where it is applicable, is quite good, which lends confidence to temperature comparisons that will be made in the present work.

\section{EXPERIMENTAL ARRANGEMENT}

Figure 3 shows the plasma generator which was used for the present study. Argon is introduced at the rear, passes forward around the water cooled central cathode containing a cooled tungsten tip and through the arc which is struck between the central cathode and the outer cylindrical, water cooled anode which forms the plasma generator wall. After arc passage the heated argon expands through the converging sonic orifice nozzle to form the self-luminous jet shown in Fig. 2c. The DC arc is rotated at high speed tangentially $\left(10^{3} \mathrm{rev} / \mathrm{sec}\right)$ to lessen electrode heat loads and promote uniformity of the hot gas by means of the magnetic field produced by a coil in series with the arc. To the eye, the arc when viewed through the nozzle appears as a shimmering sheet, well back of the nozzle entry plane.

The plasma generator is started by means of the shielded spark plug arrangement shown screwed into the top of the plasma generator in Fig. 3. A $1 \mu \mathrm{f}$ capacitor is discharged at $10 \mathrm{kv}$ across the spark plug, firing a blob of plasma between the anode and cathode to initiate the arc. This particular arrangement was used because of its ease and reliability and the fact that no high voltage pulse is sent back into the main power supply.

The gas flow diagram shown in Fig. 4 consists of parallel gas storage bottles, regulator, rotameter and rotameter pressure gauges and sonic orifice needle valves to insure constant mass flow even with chamber pressure fluctuations. The parallel system allows the quantitative mixing of two gases under flow. The gas flow system was calibrated using both a wet test meter and a large $(8000 \mathrm{cc})$ bubble meter.

The water cooled nozzle is insulated from the plasma generator and allowed to electrically float with respect to the plasma. This insures that the arc strikes to the outer cylindrical anode and not into the nozzle. This was felt to be important in order to help promote equilibrium conditions at the nozzle exit. 
Hydrodynamic calculations show that argon at the 10 atmospheres and $5000^{\circ} \mathrm{K}$ chamber conditions typical of operation takes approximately $4 \times 10^{-3}$ seconds to pass between the nozzle entrance plane and $1.59 \mathrm{~mm}$ diameter nozzle exit. The mean flow velocity in the chamber is about $30 \mathrm{~cm} / \mathrm{sec}$ at the above conditions. A very conservative estimate of $10 \times 10^{-3}$ seconds can therefore be made for the argon equilibration time at 10 atmospheres and $5000^{\circ} \mathrm{K}$ between arc passage and nozzle exit. The equilibration time may be several times longer however.

The plasma generator is routinely run for periods up to 3 hours at chamber pressures of 10.5 atmospheres, stagnation temperatures of $5500^{\circ} \mathrm{K}$ with arc currents of $250 \mathrm{~A}$, at $115 \mathrm{~V}$ using $1.4 \mathrm{gm} / \mathrm{sec}$ of argon. At $250 \mathrm{amp}$ the field coil produces 700 gauss in the arc region.

The electrical schematic showing the hookup of the $120 \mathrm{KW}, 220 \mathrm{~V}$ silicon rectifier power supply, ballast resistor, field coil and plasma generator together with the starting capacitor and its high voltage source is shown in Fig. 5.

The whole plasma generator is mounted on a cross-feed mechanism (an old shaper mount) allowing any portion of the jet to be scanned using a fixed optical system, shown in Fig. 6. The jet is brought to a secondary focus at a preslit which consists of a small hole or slit scratched on the front of a diagonal front surface mirror. The light falling on this clear area is focused on the spectrograph slit, while the remainder of the jet image is photographed by means of a camera. What one sees in the camera is an image of the jet minus that light which went through to the spectrograph. This arrangement allows correlation of the spectroscopic with the geometrical features in the jet.
Figure 7 is a front view of the overall arrangement of the experimental apparatus, showing from right to left, the standard lamp, the plasma generator, the two lenses focussed on the preslit, the camera behind used to photograph the jet and the lens which focusses the preslit onto the spectrograph slit at the left. Figure 8 is a rear view of the plasma generator and camera, showing the variable speed motor coupled to the vertical scan by a worm gear. The vertical (transverse across the jet) scan rate is monitored by means of a small model electric motor used as a generator, powering a $50 \mu \mathrm{A}$ meter.

In photoelectric operation, the jet image is scanned slowly across the preslit hole. The intensity of whatever spectral feature the monochrometer is set to is recorded as a function of transverse distance across the jet on a Brown recorder driven by means of a Keithley picoammeter.

A 1P21 photomultiplier tube driven by a stable $1 \mathrm{KV}$ power supply together with a $1 / 2$ meter JACO Ebert-Fasti monochrometer were used for the photoelectric measurements.

\section{PLASMA GENERATOR PERFORMANCE}

In order to compare spectroscopic temperatures with the local hydrodynamic gas temperature in the jet, it is necessary to determine the stagnation temperature for the gas in the chamber.

This can be done easily for a perfect gas by the sonic orifice method, which requires measurement of the mass flow of gas $\dot{m}$, the stagnation pressure $p_{c}$ and knowledge of the orifice exit area $A *$. 
We can write the mass flow through a sonic orfice (local Mach number at throat equal to one) for a perfect gas, assuming an isentropic, adiabatic expansion from the chamber as (15)

$$
\dot{\mathrm{m}}=\frac{\mathrm{p}_{\mathrm{c}} \mathrm{A}^{*}}{\sqrt{\mathrm{T}_{\mathrm{c}}}} \sqrt{\frac{\gamma \overline{\mathrm{M}}}{\mathrm{R}}\left(\frac{2}{\gamma+1}\right)^{\frac{\gamma+1}{\gamma-1}}}
$$

where $\bar{M}$ is the molecular weight and $R$ the universal gas constant.

For argon, $\gamma=1.67, \mathrm{M}=39.94$ so

$$
\dot{\mathrm{m}}=509.8 \frac{\mathrm{A}^{*} \mathrm{p}_{\mathrm{c}}}{\sqrt{\mathrm{T}_{\mathrm{c}}}} \quad \mathrm{gm} / \mathrm{sec}
$$

where $A *$ is in $\mathrm{cm}^{2}, \mathrm{p}_{\mathrm{c}}$ in atmospheres and $\mathrm{T}_{\mathrm{c}}$ in ${ }^{\mathrm{O}} \mathrm{K}$.

Now actually the mass flow is given by

$$
\grave{\mathrm{m}}=\int_{\text {exit area }} \rho * \mathrm{u} * \mathrm{dA} *
$$

where $\rho^{*}$ and $u^{*}$ are the actual density and velocity evaluated over the exit area, which includes effects of boundary layers and heat transfer. All such nonidealities are frequently lumped into a discharge coefficient $c_{n}$ defined as

$$
\mathrm{c}_{\mathrm{n}}=\frac{\dot{\mathrm{m}}_{\text {actual }}}{\dot{\mathrm{m}}_{\text {ideal }}}
$$

where the stagnation conditions are assumed the same for the ideal and actual cases.
By extending an analysis due to Simmons (16), the discharge coefficient for a converging cone-short cylindrical section orifice, including the effects of heat transfer to the wall, and assuming thin boundary layers, can be written

$$
c_{n}=1-\frac{7.1}{\sqrt{\mathrm{Re}_{\mathrm{D}}}} \sqrt{\frac{\ell}{\mathrm{D}}+\frac{\ell^{\prime}}{4 \mathrm{D}}} \mathrm{f}\left(\frac{\mathrm{T}^{*}}{\mathrm{~T}_{\mathrm{w}}^{*}}\right)
$$

where $\ell$ is the length of the straight section, $D$ the nozzle diameter and $\ell^{\prime}$ a ficticious length (dependent on such things as pressure gradient in the nozzle), which accounts for boundary layer build up in the converging section. $\operatorname{Re}_{\mathrm{D}}=\rho \mathrm{DD} / \mu$ is the Reynolds number based on exit diameter, $\rho$ the gas density, $u$ its velocity and $\mu$ the viscosity. $f\left(T^{*} / T_{w} *\right)$ is a function which accounts for the density variation within the boundary layer due to heat transfer from the gas at $\mathrm{T}^{*}$ to the wall at temperature $\mathrm{T}_{\mathrm{W}}{ }^{*}$ and is given by

$$
\mathrm{f}\left(\mathrm{T}^{*} / \mathrm{T}_{\mathrm{W}}{ }^{*}\right)=\frac{1-\ln \left(\mathrm{T}^{*} / \mathrm{T}_{\mathrm{w}}{ }^{*}\right)}{2-\left(\mathrm{T}^{*} / \mathrm{T}_{\mathrm{W}}{ }^{*}\right)}
$$

Upon evaluating the argon viscosity from Hirschfelder etal. (17), one finds that there is practically no dependence on $\mathrm{T}^{*}\left(\mathrm{~T}^{*} .02\right)$ for temperatures less than $8000^{\circ} \mathrm{K}$. Therefore for a given nozzle operating over not extreme ranges of chamber pressure we are left with the very simple formula

$$
c_{n}=1-\frac{\text { const }}{\sqrt{p_{c}}}
$$

The constant can be evaluated using room temperature argon. For the 1/16

in. diameter nozzle at 10 atmospheres, $c_{n}-1$ was found to be .0190 . 
The sonic orifice stagnation temperature was checked against the value obtained using a continuous flow calorimeter. If the mass flow of coolant having specific heat $c_{p_{1}}$, and initial temperature $T_{1}$, is $\dot{M}$, then mixing with a mass flow of hot gas $\dot{m}$, having specific heat $c_{p}$ and total temperature $T_{S}$ results in the following energy balance for the calorimeter outlet,

$$
(\dot{\mathrm{M}}+\dot{\mathrm{m}}) \mathrm{c}_{\mathrm{p}_{\text {out }}} \mathrm{T}_{\text {out }}=\dot{\mathrm{m}} \mathrm{c}_{\mathrm{p}} \mathrm{T}_{\mathrm{s}}+\dot{\mathrm{M}} \mathrm{c}_{\mathrm{p}_{1}} \mathrm{~T}_{1}
$$

The total temperatures obtained by the sonic orifice and calorimeter are compared in Fig. 9. An essential point to note on Fig. 9 is that the chamber temperature does not decrease (based on the calorimeter measurement), when a small mole fraction of $\mathrm{H}_{2}$ is added to the argon. The cluster of argon points at the low temperature end where the result of simply shutting off the $\mathrm{H}_{2}$ in each case. The $\mathrm{A}+\mathrm{H}_{2}$ points fall above the $45^{\circ}$ line because of recombination of $\mathrm{H}_{2}$ in the nozzle which is not taken account for by the simple sonic orifice equation. The $A+N_{2}$ points fall quite well along the $45^{\circ}$ line since very little $\mathrm{N}_{2}$ is dissociated at these conditions.

One basic question which always arises with a plasma jet is how should one describe its performance and how close to the obtainable limits of its performance are we at any given operating point. Usually one does this with an eye toward improving some particular feature of its operation. Here increasing the chamber temperature was felt desirable in order to get higher luminosity in the jet, and a greater degree of ionization.

Because of the complex interrelations between the many significant parameters such as arc current, voltage, mass flow and nozzle size, the use of nondimensional parameters strongly suggests itself.
Fabri (18) has presented a somewhat crude but interesting analysis that makes a start on the problem. It applies to plasma generators having transverse blown, magnetically rotated arcs striking between coaxial electrodes, as here.

He assumes the heating of the gas by the arc can be described by assuming the arc is a whirling hot rod, rotating at a frequency determined by equating the Lorentz force to the aerodynamic drag of the arc. He considers that the heat transfer from the arc can be described in terms of a Nussult number and derives expressions for the efficiency of heat transfer between the arc and the gas passing through the arc and also the overall efficiency, $\eta$, of the plasma generator. If $\eta$ is the ratio of the enthalpy flux to the input power

$$
\eta=\frac{\dot{\mathrm{m}} \mathrm{c}_{\mathrm{p}} \mathrm{T}_{\mathrm{c}}}{\mathrm{V}_{\text {arc }{ }_{\text {arc }}}^{\mathrm{I}}}
$$

then he shows one should be able to correlate $1 / \eta$ with $I_{\operatorname{arc}} /\left(A * \sqrt{p_{c}}\right)$.

In order to complete his analysis one must know the functional form of the arc voltage, $\mathrm{V}_{\text {arc }}$, which he did not.

Figure 10 shows the arc voltage plotted vs. $\sqrt{\mathrm{p}_{\mathrm{c}}}$ for argon. Two different nozzles were used in the following, having diameters of $.0625 \mathrm{in}$. and $.089 \mathrm{in}$. The reason for the square root dependence of $\mathrm{V}_{\text {arc }}$ on $\mathrm{p}_{\mathrm{c}}$ is not known but it appears to be quite accurately followed over the range of operation encountered with this plasma generator. Attempts to find other arc voltage correlations containing other parameters were not successful. 
Figure 11 shows the results of the above analysis. Assuming the square root dependence of arc voltage, isotherms on a plot of $1 / \eta$ vs. $I / A * \sqrt{p_{c}}$ are straight lines radiating from the origin.

Points having $1 / \eta$ greater than 6.5 are from the small nozzle while those with $1 / \eta<6.5$ result from the large nozzle. The two sets of points are seen to fit smoothly together and the trend shows quite clearly that a maximum chamber temperature occurs as one blows harder only up to a point (i. e., moving inward toward the origin along the set of points). This maximum chamber temperature is something of the order of $5800^{\circ} \mathrm{K}$ and occurs at a chamber pressure of about 12 atmospheres using the small nozzle.

\section{ABEL INVERSIONS OF DISCONTINUOUS FUNCTIONS}

Because of the very large variation of properties across the jet diameter at any particular downstream station, a transformation of the observed transverse intensity $I(x)$, watt/cm ster, to the actual volume emission coefficient $\varepsilon(\mathrm{r})$, watt $/ \mathrm{cm}^{3}$ ster, must be made.

For optically thin, axisymmetric sources $\mathcal{E}(\mathrm{r})$ and $\mathrm{I}(\mathrm{x})$ are related by the Abel integral equation

$$
\begin{aligned}
I(x) & =2 \int_{0}^{y} \varepsilon(r) d y \\
& =2 \int_{x}^{R} \frac{\varepsilon(r) r d r}{\sqrt{r^{2}-x^{2}}}
\end{aligned}
$$

where the path of integration is taken along the line of sight $(\mathrm{x}=$ const) through $-13-$ the source which has outer radius $R$. The analytic Abel inversion of the above equation, which is valid for continuous functions $\mathcal{E}(\mathrm{r})$ and $\mathrm{r}(\mathrm{x})$ is given by (19)

$$
\varepsilon(\mathrm{r})=-\frac{1}{\pi} \int_{\mathrm{r}}^{\mathrm{R}} \frac{\frac{\mathrm{dI}(\mathrm{x})}{\mathrm{dx}} \mathrm{dx}}{\sqrt{\mathrm{x}^{2}-\mathrm{r}^{2}}}
$$

Because the radial function $\mathcal{E}(\mathrm{r})$ has discontinuities of value and slope across the oblique shocks in the jet, Eq. 11 does not strictly hold in the present case although as we shall see it does a very good job despite this. $I(x)$ is usually known only as a set of experimental points so that numerical techniques must be used to find $\mathcal{E}(\mathrm{r})$.

There are two general philosophies for the solution of Eq. 10. One is to evaluate by numerical quadrature the analytic inversion Eq. 11 . This is the method followed by Nestor and Olsen (20), and Bochasten (21). I(x) is fitted by a local polynomial and then an analytic evaluation of Eq. 11 is performed in terms of the polynomial coefficients. The other method is to obtain a direct solution to Eq. 10 as one can do with any integral equation. Using finite differences, Eq. 10 is then usually transformed to a set of simultaneous, algebraic equations which can be solved for the unknown $\varepsilon$ at specified points. An example of this method is given by Pearce (22).

Several of these methods have been numerically evaluated for functions having radial discontinuities. The simplest radial function which was felt to simulate the relevent features of the real case consists of two piecewise continuous parabolas. These allow zero center slope, an arbitraxy slope 
and value on each side of a discontinuity between center and edge and a zero value at the outer edge. Insertion of this assumption into Eq. 10b results in a transform pair $I(x), \varepsilon(r), \quad I(x)$ and $\varepsilon(r)$ constitute a transform pair, in the same sense as a Laplace transform. For a specified radial distribution, numerical values from the transverse distribution were inserted into one of the numerical schemes, which resulted in numerical values for the radial function that could be compared to the originally specified function.

The results of such calculations, comparing an unpublished direct method similar to Pearce's with Bockastan's method, are shown in Fig. 12.

In general as seen in Fig. 12, for the same number of zones, the best quadrature methods perform slightly better than the direct methods used so far, in regions several zones removed from the jump. However, as a result of using Eq. 10b, all the quadrature methods exhibit spurious behavior near the jump, somewhat like the Gibbs phenomena for a Fourier series. Direct methods do not have this problem. In Fig. 12, the transform pairs are shown by the smooth curves, the points being the numerical results for the two cases considered.

\section{SPECTRAL CALIBRATION OF THE PHOTOMULTIPLIER}

To calibrate the system including the various electronic and optical components, grating, photomultiplier, etc., a standard tungsten flat strip lamp is placed at the jet position. The filament brightness temperature at . $65 \mu$, read by a Leeds and Northrup dissappearing filament pyrometer, is corrected to true temperature using the tungsten emissivities $\epsilon_{\lambda}(\mathrm{T})$ of de Vos, tabulated by Rutgers (23), and the known lamp envelope transmission $\tau_{\lambda}$.
Referring to Fig. 13a, the steradiancy emanating from the standard lamp is $\tau_{\lambda} \epsilon_{\lambda} B_{\lambda}(T)$, where $B_{\lambda}(T)$ is the black body function in wavelength units, measured in watt/ $\mathrm{cm}^{2}$ ster $\mu$. If $\mathrm{F}_{\lambda}$ is the overall system transmission including the grating efficiency, A the image of the source area defined by the preslit which passes through the exit slit, $\Omega$ the solid angle over which the radiation is being received from the grating, $\Delta \lambda$ the spectral bandpass of the monochrometer, which is given by the product of the reciprocal dispersion and exit slit width (exit slit width greater than or equal to entrance width), and $s_{\lambda}$ the photomultiplier sensitivity amp/watt, then the power passing through the exit slit from the lamp is $\epsilon_{\lambda} B_{\lambda}{ }^{\tau}{ }^{\Delta} \Delta \lambda F_{\lambda} A$ and the resulting photomultiplier current is given by

$$
\mathrm{i}_{\lambda}=\epsilon_{\lambda} \mathrm{B}_{\lambda} \tau_{\lambda} \Delta \lambda \mathrm{F}_{\lambda} \mathrm{As}_{\lambda}
$$

Since $A, \Omega$ and $F_{\lambda}$ are at most functions of wavelength, they can be Iumped into $s_{\lambda}$ and we can write

$$
\mathrm{i}_{\lambda}={ }_{\lambda}{ }^{\mathrm{B}} \lambda^{\tau}{ }^{\top} \Delta \lambda \mathrm{S}_{\lambda}
$$

where $\mathrm{S}_{\lambda}$ has units of amp $\mathrm{cm}^{2}$ ster/watt.

The monochrometer grating is the limiting aperture for the system.

In operation the jet is placed at the same point as was the standard lamp,

Fig. 13b. The spectral sterradiancy $I_{\lambda}(x)$ is given by

$$
I_{\lambda}(x)=\int \varepsilon_{\lambda}(x, y) d y
$$


where the integration of the volume emission coefficient $\varepsilon_{\lambda}$ is along the line of sight through the jet.

For continuum radiation, i. e. , radiation extending over a wavelength interval larger than the system bandpass $\Delta \lambda$, the spectral sterradiancy $\mathrm{I}_{\lambda}$ watt $/ \mathrm{cm}^{2}$ ster is related to the photomultiplier current $i_{\lambda}$ by

$$
\mathrm{i}_{\lambda}=\mathrm{I}_{\lambda} \Delta \lambda \mathrm{s}_{\lambda}
$$

Frequently spectral lines are superimposed on a background continuum. In order to obtain the intensity due to the line alone we must subtract the continuum. Referring to Fig. $13 \mathrm{c}$ where the shaded area $\mathrm{I}_{\text {line }}$ denotes this value, and for the usual case where the entrance and exit slits are of unequal. width resulting in the flat top shown on $\mathbf{i}_{\lambda}$, then

$$
\begin{aligned}
i_{\text {line }} & =s_{\lambda} \int_{\Delta \lambda} I_{\text {line }, \lambda} \mathrm{d} \lambda \\
& =\mathrm{I}_{\text {line }} \mathrm{s}_{\lambda}
\end{aligned}
$$

where $i_{\text {line }}$ is the current differ ence between the continuum and the flat topped line as shown.

\section{SPECTRAL LINE FORMULAS}

The formulas used for interpretation of the spectral data when local thermodynamic equilibrium (LTE) conditions apply are as follows $(24,25,26)$.

For optically thin spectral lines, the emission coefficient is given by

$$
\begin{aligned}
\varepsilon_{\lambda, \text { line }} & =\frac{1}{4 \pi} \mathrm{n}_{\mathrm{u}} \mathrm{A}_{\mathrm{u} \ell} \mathrm{h} \nu \\
& =\frac{1}{4 \pi} h \nu \frac{\mathrm{n}}{\mathrm{Z}} g_{\mathrm{u}} A_{\mathrm{u} \ell} e^{-\mathrm{E}_{\mathrm{u}} / \mathrm{kT}} \frac{\text { watt }}{\mathrm{cm}^{3} \text { ster }}
\end{aligned}
$$

where $\mathrm{n}_{\mathrm{u}}$ is the upper state population, $\mathrm{h} \nu=\mathrm{E}_{\mathrm{u}}-\mathrm{E}_{\ell}$ is the energy difference between upper and lower energy levels $E_{u}$ and $E_{\ell}, A_{u \ell}$ is the Einstein transition probability for the particular transition, $g_{u}=2 J_{u}+1$ is the statistical weight of the upper state, $\mathrm{n}$ the total number density of atoms and $\mathrm{Z}$ is the electronic partition function for the atom. The other symbols have their usual meaning.

The Saha equation relating the number densities of ions, atoms and electrons is

$$
\frac{\mathrm{n}_{+} \mathrm{n}_{\mathrm{e}}}{\mathrm{n}}=\frac{2 \mathrm{Z}+}{\mathrm{Z}} \frac{\left(2 \pi \mathrm{m} \mathrm{e}^{\mathrm{kT}}\right)^{3 / 2}}{\mathrm{~h}^{3}}-\mathrm{e}^{3} / \mathrm{kT}
$$

where $V_{0}$ is the ionization energy of the atom (corrected for ionization energy lowering if necessary) and $n_{+}$is the ion density.

The continuum radiation due to free-free and free-bound interaction between the ions and electrons for frequencies less than the limiting frequency $\nu_{c}$, is given by (27)

$$
\varepsilon_{\nu}=5.43 \times 10^{-46} \mathrm{z}_{\text {eff }}^{2} \frac{\mathrm{n}_{+} \mathrm{n}_{\mathrm{e}}}{\mathrm{T}_{\mathrm{e}}} \quad, \quad \text { watt } / \mathrm{cm}^{3} \text { ster } \mathrm{sec}^{-1}
$$

where $\mathrm{Z}_{\text {eff }}$ is the effective nuclear charge seen by the electron and $\mathrm{T}_{\mathrm{e}}$ the
$-17-$
$-18-$ 
kinetic temperature of the electrons. The energy levels which lie below the ionization limit by an amount less than $h \nu_{c}$ are assumed to be close enough together to form a continuum.

The theory of the linear Stark broadening in $\mathrm{H}$ has been worked out in detail by Griem (28). The line broadening depends strongly on the electron density and is only a weak function of $\mathrm{T}$. The full width at half intensity for $\mathrm{H} \beta$ at $10,000^{\circ} \mathrm{K}$, fitted to the values given by Hill (29) is

$$
\lambda_{1 / 2} \stackrel{\stackrel{\AA}{\mathrm{A}})}{ }=9.2 \times 10^{-11} \mathrm{n}_{\mathrm{e}} \cdot 69
$$

Equation 20 is not dependent on LTE.

These equations can be manipulated in many ways for a particular application. The intensity per $\mathrm{H}$ atom for the $\mathrm{H} \beta$ line as a function of $\mathrm{T}$ is shown in Fig. 14. Figure 15 is a plot of the intensity ratio of $\mathrm{CaI} / \mathrm{CaII}$ as a function of $\mathrm{T}$ for particular values of $\mathrm{n}_{\mathrm{e}}$.

In order to verify the existence of local thermodynamic equilibrium (LTE), one must measure the energy distribution parameter $\mathrm{T}$ for as many different energy distributions as possible and compare the values obtained. In the following we shall compare the kinetic or hydrodynamic heavy particle temperature, the Saha temperature, the Boltzmann temperature, characterizing the distribution of excited bound states among themselves, the absolute temperature which characterizes the population of excited states relative to the ground state, and the kinetic temperature of the electrons. We shall see that in our case these are not all compatible.

\section{RESULTS AND DISCUSSION}

Figures $16 \mathrm{a}, 16 \mathrm{~b}$, and $16 \mathrm{c}$ are photographic spectra taken with a dual prism Huet spectrograph using a slit preslit placed transversly across the jet. The lowest spectra in Fig. 16a, 16b, and $16 \mathrm{c}$ were taken just outside the nozzle exit, the center ones about $2 / 3$ of the way to the Mach disk and the top spectra just behind the Mach disk. Figure 16a was pure argon at $7.83 \mathrm{~atm}, \mathrm{~T}_{\mathrm{c}}=4910^{\circ} \mathrm{K}, 290 \mathrm{~A}, 95 \mathrm{~V}, \dot{\mathrm{m}}_{\mathrm{A}}=1.10 \mathrm{gm} / \mathrm{sec}$ and required $5 \mathrm{sec}-$ ond exposures. When $\mathrm{H}_{2}$ was added to the argon upstream of the arc in Fig. $16 \mathrm{~b}$, the conditions were $\mathrm{p}_{\mathrm{c}}=8.05 \mathrm{~atm}, \dot{\mathrm{m}}_{\mathrm{A}}=1.13 \mathrm{gm} / \mathrm{sec}, \mathrm{x}_{\mathrm{H}_{2}}($ cold $)=$ $.0225,225 \mathrm{~A}, 125 \mathrm{~V}, \mathrm{~T}_{\mathrm{c}}=4950^{\circ} \mathrm{K}$, but 50 second exposures were necessary leaving the slit unchanged.

For Fig. 16c, . 0594 cold mole fraction of $\mathrm{N}_{2}$ was added to $1.09 \mathrm{gm} / \mathrm{sec}$ argon with $\mathrm{p}_{\mathrm{c}}=8.04 \mathrm{~atm}, 235 \mathrm{~A}, 121 \mathrm{~V}, \mathrm{~T}_{\mathrm{c}}=5030^{\circ} \mathrm{K}$. The exposures again were 50 seconds.

The majority of the lines in all spectra are argon I. Note in Fig. 16b the Stark broadened Balmer series lines of CaI and CaIl are present as are BaII. The tungsten electrode was impregnated with $\mathrm{Ca}$ and $\mathrm{Ba}$ at the time of manufacture. Very weak lines of $\mathrm{Al}, \mathrm{Cu}, \mathrm{Cd}$, and $\mathrm{Zn}$ have been found.

The continuum radiation, which appears strongly in each case near the exit and less so behind the Mach disk, is probably due to free-free, freebound processes of the ions and electrons.

Note the presence of the $\mathrm{N}_{2}$ second positive system in Fig. 16a taken just behind the Mach disk and its absence in the exposures taken at the same position in Fig. $16 \mathrm{~b}$ and $16 \mathrm{c}$, even though these exposures were 10 times 
longer. This radiation arising from $\mathrm{N}_{2}$ being entrained into the jet from the atmosphere, is apparently due to a selective, nonthermal excitation given by excited argon atoms. In color pictures of the jet, as well as by eye, one can see very clearly the intense bluish radiation from the $\mathrm{N}_{2}$ which emanates most strongly from the mixing zone along the jet boundary.

The band systems occurring in Fig. $16 \mathrm{c}$ are all $\mathrm{N}_{2}^{+}$. When $\mathrm{N}_{2}$ is added to the argon one notices a very faint greenish feathery plume extending out beyond the rather bright structure one sees in Fig. 2c. It is continuum radiation apparently from the reaction $\mathrm{NO}+\mathrm{O} \rightarrow \mathrm{NO}_{2}+\mathrm{h} \nu$. Note the enhanced luminosity of the BaIl lines when $\mathrm{N}_{2}$ is added in Fig. $16 \mathrm{c}$.

Neither the spectral lines nor the continuum is polarized. The $\mathrm{H}$ which appears in Fig. 16a is due to water vapor.

Noting the exposure times for each spectrum, we can clearly see the profound drop in luminosity which occurs when a few percent of either $\mathrm{H}_{2}$ or $\mathrm{N}_{2}$ is added to the argon prior to arc passage. We will return to this point later.

When several percent $\mathrm{He}$ or $\mathrm{Ne}$ is added there is no change in either the luminosity or in the character of the spectra.

Figures $17,18,19$, and 20 present a fairly detailed picture of the $\mathrm{H} \beta$ radiation across the jet at three downstream points. Figure 17, taken through the camera shown in Fig. 6, shows the position of the preslit on axis right at the exit, $2 / 3$ of the way between the exit and the Mach disk, and just behind the Mach disk. The operating conditions are given on Fig. 17.

The Brown recorder traces in Fig. 18 show the transverse intensity distribution of $\mathrm{H} \beta$ across the jet at these three stations. Observe the rather good symmetry. The $\mathrm{H}$ was present in the jet probably as a water vapor impurity in the argon. The noise is due to intensity fluctuations in the jet during the 5 minute scan across the jet. The finite preslit hole size $(.14 \mathrm{~mm})$, shown scale size on Fig. 18, rounds off somewhat the otherwise rather abrupt intensity changes. The center of each curve was determined by folding, and if any asymmetry was present an average value for the two halves was chosen.

Figure 19 shows the Abel inverted curves from Fig. 18. Even though some deliberate smoothing was performed, any small scatter remaining in the transverse points is enhanced by the inversion.

Note that on the jet centerline the $\mathrm{H} \beta$ intensity drops only one order of magnitude between the jet exit and $\mathrm{Z}=1.9 \mathrm{~mm}$, although the characteristics solution indicates a Mach 3.2 flow, at this point. The temperature is down here by a factor of 3.3 and the density down by a factor of 6 , compared to values at the exit. Referring to Fig. 14 we see that a much larger intensity drop should have occurred with this temperature change. Observe the fairly large intensity variation across the exit plane. At $\mathrm{Z}=1.90 \mathrm{~mm}$ we note the smooth decrease in luminosity radially until the oblique intercepting shock is crossed.

At $\mathrm{Z}=3.18 \mathrm{~mm}$ note the relatively uniform conditions which occur across the whole region behind the Mach disk. The large peak at $\mathrm{r}=.6 \mathrm{~mm}$ is the result of crossing the slip line which can be seen best in the $Z=0$ picture of Fig. 17. The sharp drop off outside of this is the result of crossing the oblique reflected shock. 
The theoretical radial distribution of density and temperature obtained from a characteristics jet solution for argon expanding from 7 atmospheres at a point 2.23 nozzle radii downstream from the exit plane is given in Fig. 20. The qualitative similarity to the luminosity plot for $\mathrm{Z}=1.90 \mathrm{~mm}$ is evident, until mixing, which is neglected in the characteristics solution, becomes dominant.

Figure 21a shows the $\mathrm{H} \beta$ line profile measured at the exit with a spectral resolution of $.4 \AA$. The continuum has been subtracted. A fit to the theoretical curve (Fig. 21b) is shown. The values of $n_{e}$ obtained using other members of the Balmer series all fell within $10 \%$ of this value, $n_{e}=7 \times 10^{14}$.

The continuum intensity as a function of wavelength is shown in Fig. 22. Assuming the electron kinetic temperature to be the local hydrodynamic temperature of $3000^{\circ} \mathrm{K}$ and inserting $\mathrm{n}_{\mathrm{e}}=7 \times 10^{14}$ found from the Stark broadening, one finds $\mathrm{z}_{\text {eff }}^{2} \sim 3$ for agreement with Eq. 19.

Figure 23 is a plot of population vs. energy level which, for a Boltzmann distribution, should yield a straight line having a slope of $1 / \mathrm{kT}$. The slopes are fairly constant, except for perhaps the one at $r=0$, but the value of $5200^{\circ} \mathrm{K}$ characteristic of these curves is far above the calculated hydrodynamic or kinetic temperature of about $3000^{\circ} \mathrm{K}$ at the exit plane.

The watts/ster per $\mathrm{H}$ atom for $\mathrm{H} \beta$ at the exit as a function of the number density of $\mathrm{H}$ atoms at the exit is given in Fig. 24. The tables listed in Penner (30) were used to calculate the density of atoms at the calculated hydrodynamic exit conditions, $3000^{\circ} \mathrm{K}$ and $3.5 \mathrm{~atm}$, as a function of the known cold mole fraction of $\mathrm{H}_{2}$. The intensity per $\mathrm{H}$ atom falls as $\mathrm{n}_{\mathrm{H}}{ }^{-4.4}$ over the somewhat limited range covered. Referring to Fig. 14 , at $\mathrm{n}_{\mathrm{H}}=1 \times 10^{17}$ we find $\mathrm{T}_{\text {abs }}=7600^{\circ} \mathrm{K}$, at the exit. The order of magnitude change in radiant power shown in Fig. 14 corresponds to a $10 \%$ change in the absolute temperature.

The measured line ratio CaI $\lambda 4227 / \mathrm{CaII} \lambda 3934$ was .77 at the exit, which, when coupled with $n_{e}=7 \times 10^{14}$ found from the Stark broadening, yields $\mathrm{T}_{\text {Saha }}=5080^{\circ} \mathrm{K}$ from Fig. 15 .

We summarize these conditions in Table I. The relevent collision crosssections were taken from Refs. 31 and 32 . The collision frequency $\nu$, was calculated using $\nu=n Q<v>$ where $\mathrm{n}$ is the number density of colliding species, $\mathrm{Q}$ is the crossection and $\langle\mathrm{v}\rangle$ is the mean speed of the colliding species.

The equilibration time of the gas between arc passage and nozzle exit is greater than $10^{-2}$ seconds.

Substantially the same absolute temperature is obtained using one of the argon lines rather than $\mathrm{H} \beta$.

$\nu_{\mathrm{H}_{2} \text {, meta }}$ refers to the collisional deexcitation of metastable argon atoms by $\mathrm{H}_{2}$.

We note the following points which seem important.

1. The $\mathrm{H}$ excitation falls very rapidly with increasing hydrogen concentration as shown on Fig. 24.

2. The $\mathrm{N}_{2}$ second positive system disappears if a few percent $\mathrm{H}_{2}$ or $\mathrm{N}_{2}$ are added to the argon upstream of the arc, but no change in either the argon line radiation, nor in the $\mathrm{N}_{2}$ second positive system, occurs when Ne and He are added. 
TABLE I

\section{PLASMA JET CONDITIONS}

$$
\begin{aligned}
& \text { Chamber } \\
& \mathrm{p}_{\mathrm{c}}=7.03 \mathrm{~atm} \\
& \mathrm{~T}_{\mathrm{c}}=3945^{\circ} \mathrm{K} \\
& \mathrm{n}_{\mathrm{A}}=1.24 \times 10^{19} \mathrm{cc}^{-1} \\
& \mathrm{X}_{\mathrm{H}_{2}}=.0068 \\
& \mathrm{x}_{\mathrm{H}}=.0453 \\
& \nu_{\mathrm{eH}}=7 \times 10^{10} \mathrm{sec}^{-1} \\
& \nu_{\mathrm{eA}}=1.4 \times 10^{10} \mathrm{sec}^{-1} \\
& \nu_{\mathrm{HA}}=4 \times 10^{9} \mathrm{sec}^{-1} \\
& \nu_{\mathrm{H}_{2} \mathrm{~A}_{\text {meta }}}=10^{5} \mathrm{sec}^{-1} \\
& B=700 \text { gauss } \\
& \mathrm{I}=250 \mathrm{~A} \\
& \mathrm{~V}=120 \text { volts }
\end{aligned}
$$

$$
\begin{aligned}
\mathrm{p}_{\mathrm{ex}} & =3.42 \mathrm{~atm} \\
\mathrm{~T}_{\mathrm{ex}} & =2955^{\circ} \mathrm{K} \\
\mathrm{n}_{\mathrm{A}} & =8.14 \times 10^{18} \mathrm{cc}^{-1} \\
\mathrm{n}_{\mathrm{H}} & =1.01 \times 10^{17} \mathrm{cc}^{-1} \\
\mathrm{X}_{\mathrm{H}_{2}} & =.0250 \\
\mathrm{X}_{\mathrm{H}} & =.0120 \\
\mathrm{~T}_{\text {Balmer }} & =5200^{\circ} \mathrm{K} \\
\mathrm{T}_{\mathrm{H} \beta} & =7600^{\circ} \mathrm{K} \\
\mathrm{T}_{\text {Saha }} & =5080^{\circ} \mathrm{K} \\
\mathrm{n}_{\mathrm{e}} & =7 \times 10^{14} \mathrm{cc}^{-1} \\
\mathrm{~B} & =100 \text { gauss }^{\circ}
\end{aligned}
$$

3. Referring to Fig. $16 \mathrm{~b}$ and Fig. 24 we note that even though the hydrogen radiation falls with increasing hydrogen concentration, the argon line radiation has fallen even faster. Both however are many orders too high. Referring to Fig. 14 we see that the $\mathrm{H} \beta$ radiation changes by 12 orders between $7600^{\circ} \mathrm{K}$ and $3000^{\circ} \mathrm{K}$.

4. At the collision frequencies noted in Table I, thermal equilibrium from collisions should certainly have occurred in $10^{-2}$ seconds.

5. Only the second positive system has been seen in the jet. If this were due to thermal excitation, one would also expect to see some members of the Herman-Kaplan system which fall in the green, but none have been seen.

Figure 25 is an energy level diagram for $\mathrm{A}, \mathrm{H}, \mathrm{N}_{2}$, $\mathrm{He}$ and $\mathrm{Ne}(33,34)$, and shows only some of the lower levels for the atoms. The ionization energy is denoted by IP. Most of the visible lines in A arise from transitions between the levels grouped around $13.2 \mathrm{ev}$ down to those around $11.7 \mathrm{ev}$. The apparent explanation of many of the points noted is a large over population of some, if not all, of the quartet of first excited levels in argon around 11. $7 \mathrm{ev}$ shown on Fig. 25. Such atoms are apparently formed in the arc and many remain in an excited state until they get outside the nozzle, unless some other kind of atom is present with which collisions of the second kind can occur. Collisions of the second kind can be made with $\mathrm{H}$ and the $\mathrm{N}_{2}$ second positive upper state which lie below the excited argon levels. Such collisions would deexcite the argon and excite the other partner. Collisions of the second kind are not possible for argon with either $\mathrm{Ne}$ or $\mathrm{He}$. Note that the argon 
level around 11. 7 ev can excite the $\mathrm{N}_{2}$ second positive system but not the Herman-Kaplan system.

Although two of the four first excited states are metastable for radiation to the ground state (35), the large numbers of collisions here would seem to preclude any excess build up of these levels. The radiative transition probability for the other two states down to the argon should be quite large since they are resonance transitions.

Thermal excitation of levels $11.7 \mathrm{ev}$ above the ground state is not likely with a population having a kinetic temperature on the order of $5000^{\circ} \mathrm{K}$ or $1 / 2 \mathrm{ev}$. Once however, a population has been built up in these first excited levels, thermal excitation could populate the higher levels.

The explanation that appears most reasonable (36)* in explaining the large number of excited argon atoms, is the trapping of the argon resonance radiation.

Even at temperatures on the order of $15,000-20,000^{\circ} \mathrm{K}$ which may occur in the high current, highly blown arc, most argon atoms are still in their ground state. Radiation at the resonance wavelengths has a high probability of being absorbed by an argon atom and a short time later being reemitted in a random direction with respect to the initial direction. Such a random walk leads to a diffusion of photons through the gas rather than their direct escape.

*Suggested to the author by H. Griem, University of Maryland.
The controlling factor in determining the escape of photons, however, is their diffusion in frequency out to the line wings where they can more readily escape from the plasma so that the e folding time depends on the spectral line shape.

Calculations show that for typical chamber conditions with $n=10^{19}$ and $\mathrm{T}=5000^{\circ} \mathrm{K}$ that the argon resonance line profile is substantially doppler over most of its core. The Voigt profile (26) has a ratio of collision broadening to doppler width

$$
a=(\Gamma / 4 \pi) / \Delta \nu_{0}=.05
$$

The e-folding time for resonance radiation is given by $(36,37)$ as

$$
t=\frac{1}{A_{u l} g\left(\tau_{0}\right)} \quad \sec
$$

where $g$ is the escape factor which is a function of the optical depth $\tau_{0}$ at the center of the line, and $A_{u l}$ is the Einstein transition probability. The optical depth is given by

$$
\tau_{0}=\kappa_{0} \mathrm{~L}
$$

where $\kappa_{0}$ is the absorption coefficient at the line center and $L$ a distance that is about $1 / 2$ the smallest plasma dimension.

For a doppler line

$$
g\left(\tau_{0}\right)=\frac{1}{\tau_{0} \sqrt{\pi \ln \tau_{0}}}
$$

and one can show 


$$
\kappa_{0}=1.16 \times 10^{-6} \sqrt{\frac{\mathrm{M}}{\mathrm{T}}} \lambda \mathrm{n}_{\ell} \mathrm{f}_{\ell \mathrm{u}}
$$

$M$ is the molecular weight and, $\lambda$ is the wavelength of the radiation, $n_{\ell}$ is the number density in the ground state and $f_{\ell u}$ is the $f$ value for the particular transition.

Assuming $\mathrm{n}_{\ell}=10^{19}, \mathrm{f}_{\ell \mathrm{u}} \sim 1, \mathrm{M}=40, \mathrm{~T}=5000^{\circ} \mathrm{K}$, then $\kappa_{0} \sim 1 \times 10^{7} \mathrm{~cm}^{-1}$. The $f$ value and $A$ value for a transition are related by (26)

$$
\mathrm{A}_{\mathrm{u} \ell}=\frac{.666}{\lambda^{2}} \frac{\mathrm{g}_{\ell}}{\mathrm{g}_{\mathrm{u}}} \mathrm{f}_{\ell \mathrm{u}}
$$

so that $\mathrm{A}_{\mathrm{ul}} \sim 2 / 3 \times 10^{9}$. We find the escape time from a $1 \mathrm{~mm}$ volume to be on the order of $10^{-2}$ seconds. This is of the same order as the transit times.

It is interesting to note that in contradiction to most nonequilibrium mechanisms, resonance trapping becomes more of a problem as the density increases.

In view of the various approximations made, all one can say with certainty is that resonance trapping must be considered.

\section{SUMMARY}

In summary, the argument to explain the plume luminosity that seems $m$ most convincing here is that the resonance radiation is trapped in the argon up near the arc, then is convected along with the argon, diffusing slowly outward to a boundary, where it escapes. This radiation provides optical excitation of the argon first excited levels. The addition of a gas with which the argon can make collisions of the second kind, serves to collisionally deexcite the argon and quench the resonance radiation (38) leading to the large decreases noted in the luminosity of both the argon and the impurity atoms.

The hydrogen's own resonance radiation is not trapped because of the large Stark broadening. The $\mathrm{H} \beta$ radiation is reflecting a non-LTE population induced in the first excited state of hydrogen through the collisions of the second kind with the argon, and the subsequent further excitation by ordinary thermal collision process.

The reason this phenomena is of importance here, is that we have removed the gas from its point of excitation expecting it to undergo a hydrodynamic cooling down to the point of observation. In shock tubes and arcs, where one looks at the gas at the point of excitation, it is precisely this resonance trapping which provides LTE in situations where on the basis of collisions alone it would not be expected (39).

In the present situation however the resonance radiation seems to be responsible for a whole chain of nonequilibrium phenomena. Further studies are underway to test this conjecture.

The work reported herein was conducted by the Institute of Science and Technology for the Advanced Research Projects Agency, U. S. Department of Defense, Contract SD-91 (ARPA Order 236) as a part of Project DEFENDER (research on and defense against ballistic missiles). 


\section{REFERENCES}

1. Jahn, R. E., "Temperature Distribution and Thermal Efficiency of Low Power Arc Heated Plasma Jets," Brit. Jour. Appl. Phys., Vol. 14, 1963 , p. 585.

2. Cremers, C.J. and Pfender, E., "Thermal Characteristics of a High and Low Mass Flux Argon Plasma Jet, "Aerospace Research Laboratories, Office of Aerospace Research, ARL 64-191, Nov. 1964.

3. McGregor, W. K. , "Measurement of Temperature in the Jet from an Arc Plasma Generator Using a Spectrometric Method," Dissertation, University of Tennessee, Aug. 1961.

4. Brewer, L. E., Jr. , "Plasma Radiation Resulting from an Over Population of Atoms in the Metastable State," Dissertation, University of Tennessee, Mar. 1965.

5. Dickerman, P. J. and Morris, J. C. , "Experimental Studies of the Temperature in a Field-Free Plasma, "Optical Spectrometric Measurements of High Temperatures, ed. P.J. Dickerman, University of Chicago Press, 1961 , p. 170.

6. Peters, Th., "Erzeugung von Plasmastrahlen hoher Temperaturen und Geschwindigkeiten," Astronautica Acta, Vol. VII, Fasc. 2-3, 1961, p. 150 .

7. Watson, M. D., Ferguson, H. I. S., and Nicholls, R. W., "Electrical and Optical Studies of the Argon Plasma Jet," Canadian J. of Physics, Vol. 41, 1963.

8. Adamson, T. C., Jr., "The Structure of the Rocket Exhaust Plume without Reaction at Various Altitudes, "in Supersonic Flow, Chemical Processes, and Radiative Transfer, Pergamon Press, 1964.

9. Adamson, T. C., Jr. and Nicholls, J. A., "On the Structure of Jets from Highly Underexpanded Nozzles into Still Air," J. Aero/Space Sciences, Vol. 26, No. 1, Jan. 1959.

10. Love, E. S., Grigsby, C. E., Lee, L. P. , and Woodling, M. J., "Experimental and Theoretical Studies of Axisymmetric Free Jets, "NASA TR-6, 1959.

11. Prandtl, L., "Űber die stationären Wellen in einem Gasstrahle, " Physik Z., Vol. 5, 1904; also, "Neue Untersuchungen über die strömende Bewegung der Gáse und Dämpfe," Physik Z., Vol. 8, 1907, pp. 23-32.

12. Wilcox, D. E., Weir, A., Jr., Nicholls, J. A., and Dunlap, R., "Location of Mach Discs and Diamonds in Supersonic Air Jets," J. Aero Sciences, Vol. 24, No. 2, Feb. 1957.

13. Crist, S. A., Glass, D.R., and Sherman, P.M., "An Experimental Study of the Shock Structure of a Jet Exhausting from a Highly Underexpanded Sonic Nozzle, "Univ. of Mich. , BAMIRAC Report 04613-79-T, Jan. 1965.
14. Ladenburg, R., Van Voorhis, C. C., and Winckler, J., "Interferometric Studies of Faster than Sound Phenomena. Part II. Analysis of Supersonic Air Jets," Physical Review, Vol. 76, No. 5, Sept. 1949.

15. Shapiro, A.H., The Dynamics and Thermodynamics of Compressible Fluid Flow, Mass. Inst. Tech., Ronald Press, N. Y., Vol. I, 1953, p. 85.

16. Simmons, F.S., "Analytic Determination of the Discharge Coefficients of Flow Nozzles," Lewis Flight Propulsion Lab. , NACA TN 3447, Feb. 1955 .

17. Hirschfelder, J. O., Curtiss, C. F., and Bird, R. B., Molecular Theory of Gases and Liquids, John Wiley and Sons, Inc., N. Y., 1954.

18. Fabri, J., "Analyse des Resultats Experimentaux Obtenus sur un Arc a l'Argon, " AGARDograph 84, Pt, 2, Sept. 1964, p. 709.

19. Hildebrand, F.B., Methods of Applied Mathematics, Prentice-Hall, Inc. , N. J., Dec. 1958.

20. Nestor, O. H. and Olsen, H. N., "Numerical Methods for Reducing Line and Surface Probe Data," SIAM Rev., Vol. 2, No. 3, July 1960.

21. Bockasten, K., "Transformation of Observed Radiances into Radial Distribution of the Emission of a Plasma," J. Optical Soc. of Am. , Vol. 51, No. 9, Sept. 1961.

22. Pearce, W. J., "Plasma-Jet Temperature Measurement," Optical Spectrometric Measurements of High Temperatures, ed, P.J. Dickerman, Univ. of Chicago Press, 1961, p. 125.

23. Rutgers, G. A. W., "Temperature Radiation of Solids," Handbuch der Physik, S. Flugge, ed., Vol. XXVI, Springer, 1958, p. 129.

24. Griem, H.R., Plasma Spectroscopy, McGraw-Hill, N. Y., 1964

25. Drawin, H-W and Felenbok, P., Data for Plasmas in Local Thermodynamic Equilibrium, ed. Gauthier-Villars, Paris, 1965.

26. Aller, L. H. , Astrophysics The Atmospheres of the Sun and Stars, Ronald Press Co。, N. Y., 1963

27. Finkelnburg, W. and Peters, Th., Kontinuierliche Spektren, Hundbuch der Physik, Vol. XXVIII, Springer-Verlag, ed. S. Flugge, 1957, pp. 79-204.

28. Griem, H. R., Kolb, A. C., and Shen, K. Y., "Stark Broadening of Hydrogen and Hydrogenic Neutral and lonized Helium Lines in a Plasma," U. S. Naval Res. Lab. , NRL Rept. 5805, Aug. 1962.

29. Hill, R. A. "Tables of Electron Density as a Function of the Halfwidth of Stark-Broadened Hydrogen Lines, "Quant. Spectrosc. Radiat. Transfer, Vol. 4, 1964, pp. 357-861. 
30. Penner, S.S., Chemistry Problems in Jet Propulsion, Pergamon Press, 1957.

31. Brown, S. C., Basic Data of Plasma Physics, Tech. Press of Mass. Inst. Tech. and John Wiley and Son, Inc., 1959

32. Phelps, A.V. and MoInar, J.P., "Lifetimes of Metastable States of Noble Gases, "Physical Rev, , Vol. 89, No. 6, Mar. 1953.

33. Pearse, R.W.B. and Gaydon, A. G., The Identification of Molecular Spectra, John Wiley and Sons, Inc. , N. Y., 1950.

34. Moore, C. E. , Atomic Energy Levels, Circular of the National Bureau of Standards 467, Vol. I, June 1949.

35. Mitchell, A. C. G. and Zemansky, M.W.; Resonance Radiation and Excited Atoms, Cambridge Univ. Press, 1961.

36. Holstein, T., phys. Rev. 72, 1212 (1947); also phys. Rev. 83, 1159 (1951).

37. McWhirter, R.W.P., "Spectral Intensities, " Plasma Diagnostic Techniques, ed. by Huddlestone, R. H. and Leonard, S. L., Academic Press, Ch. 5 , p. 201,1965 .

38. Brewer, L. E. and McGregor, W. K., "The Radiative Decay of Metastable Argon Atoms in a Low-Density Argon Plasma Stream, " Rocket Test Facility, ARO, Inc. , Report No. AEDC-TDR-63-5, Jan. 1963.

39. Griem, H. R, "Validity of Local Thermal Equilibrium in Plasma Spectroscopy," Phys. Rev., Vol. 131, No. 3, Aug. 1963, p. 1170.

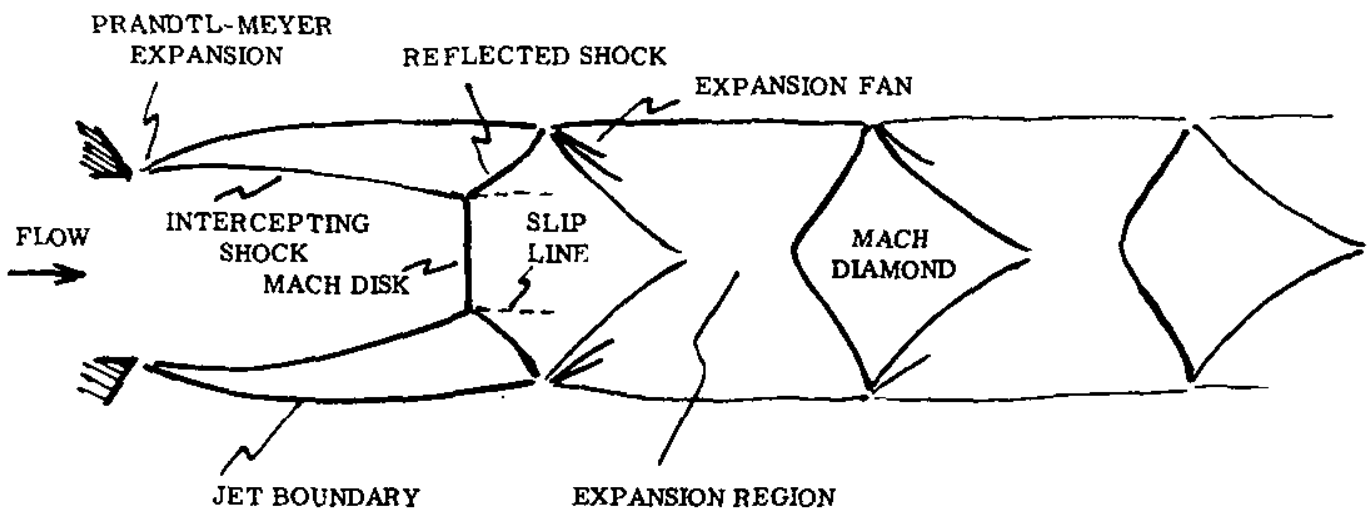

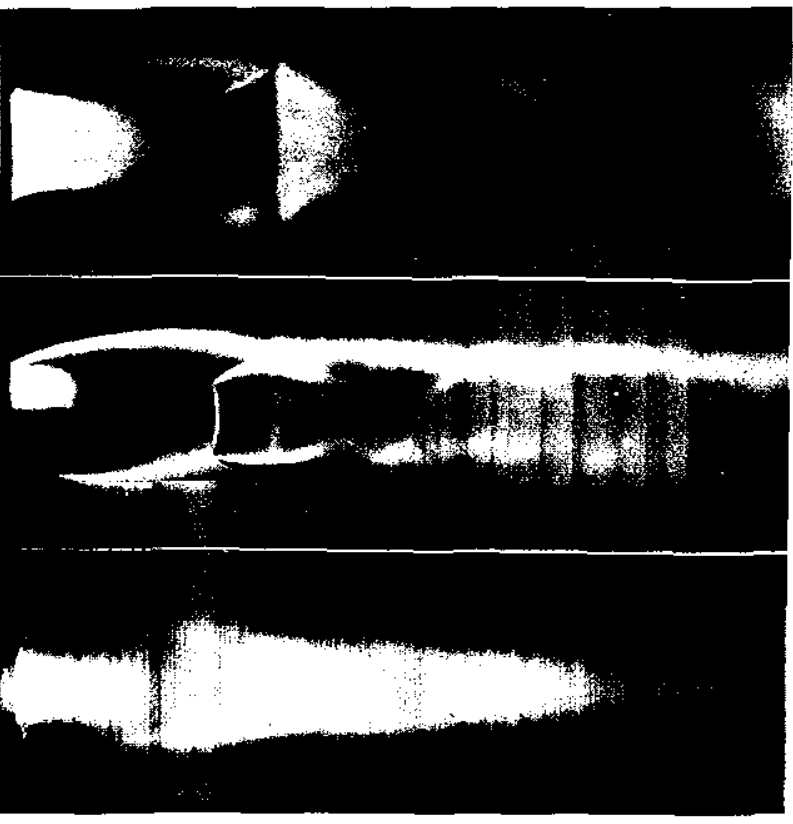

FIG. 2

\section{SONIC ORIFICE UNDEREXPANDED JET STRUCTURE}

2a Schlieren picture room temperature air $p_{c}=7.5 \mathrm{~atm}$ Xnife edge perpendicular to jet axis

$2 \mathrm{~b}$ Schlieren picture room temperature air $\mathrm{p}_{\mathrm{c}}=7.5 \mathrm{~atm}$ Knife edge parallel to jet axis

$3 \mathrm{~b}$ Self-luminous picture, $5000^{\circ} \mathrm{K}$ argon $\mathrm{p}_{\mathrm{c}}=9.4 \mathrm{~atm}$

FIG. 1 HYDRODYNAMIC STRUCTURE OF AN UNDER EXPANDED JET 


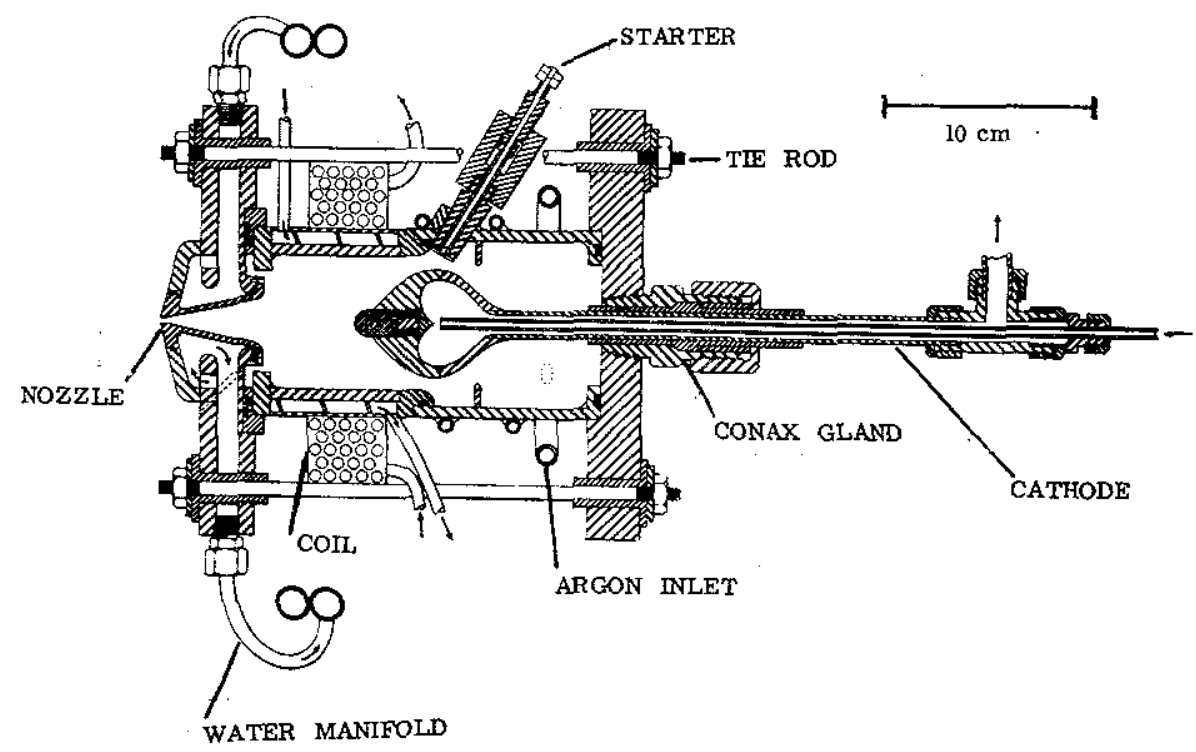

FIG. 3 CROSSECTIONAL VIEW OF DC $30 \mathrm{KW}, 10$ ATM PLASMA GENERATOR

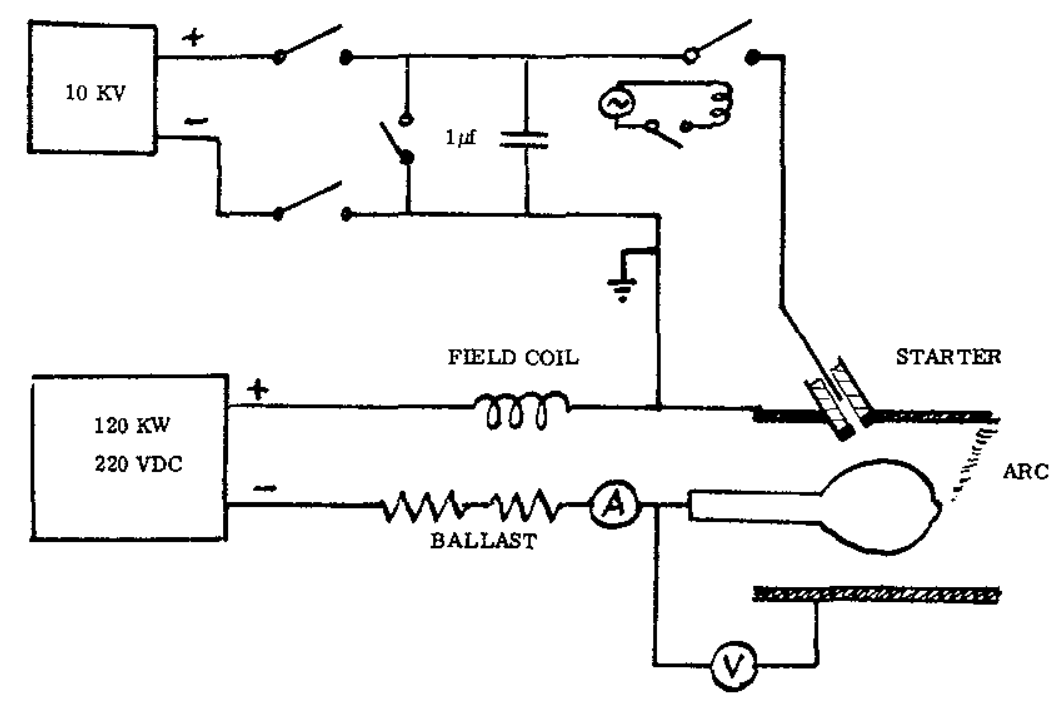

ELECTRICAL POWER AND STARTER SCHEMATIC FIG. 5

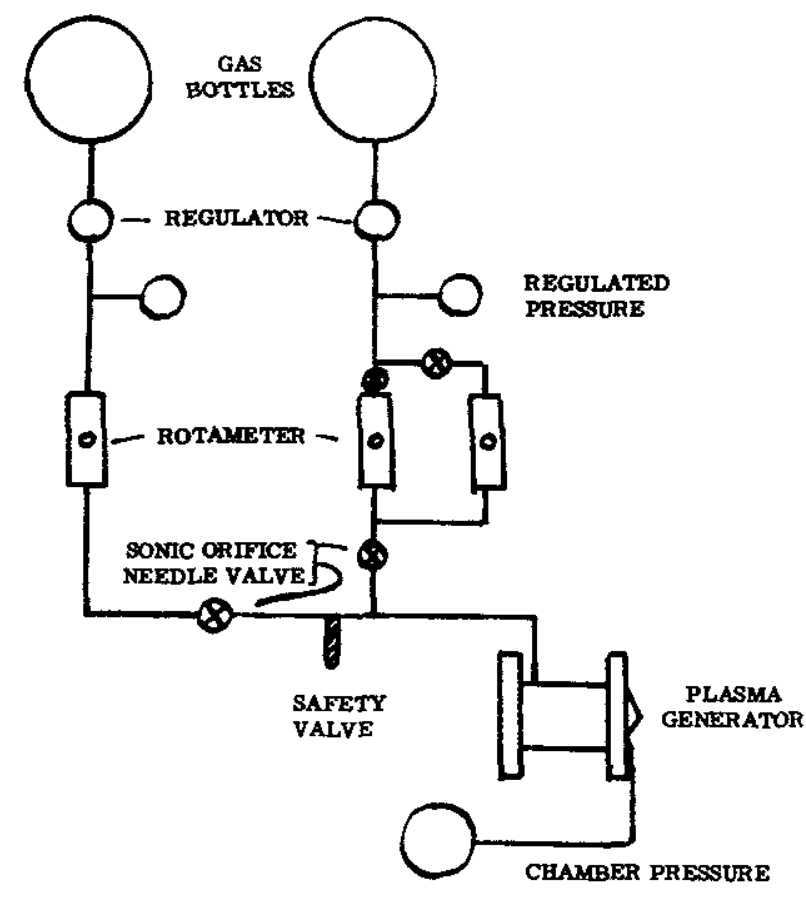

GAS FLOW SYSTEM

FIG.

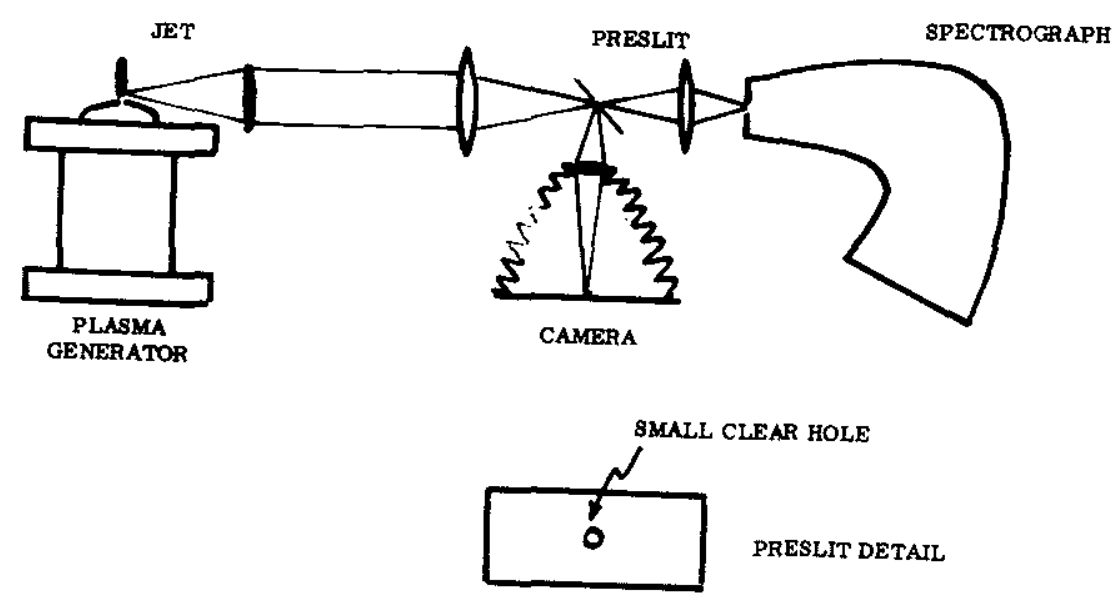

OPTICAL SETUP

FIG. 6 


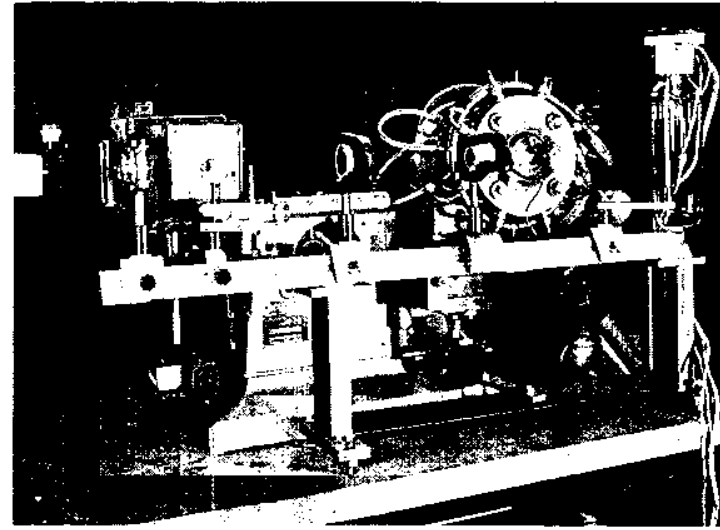

FIG. 7 FRONT VIEW OF EXPERIMENTAL SETUP

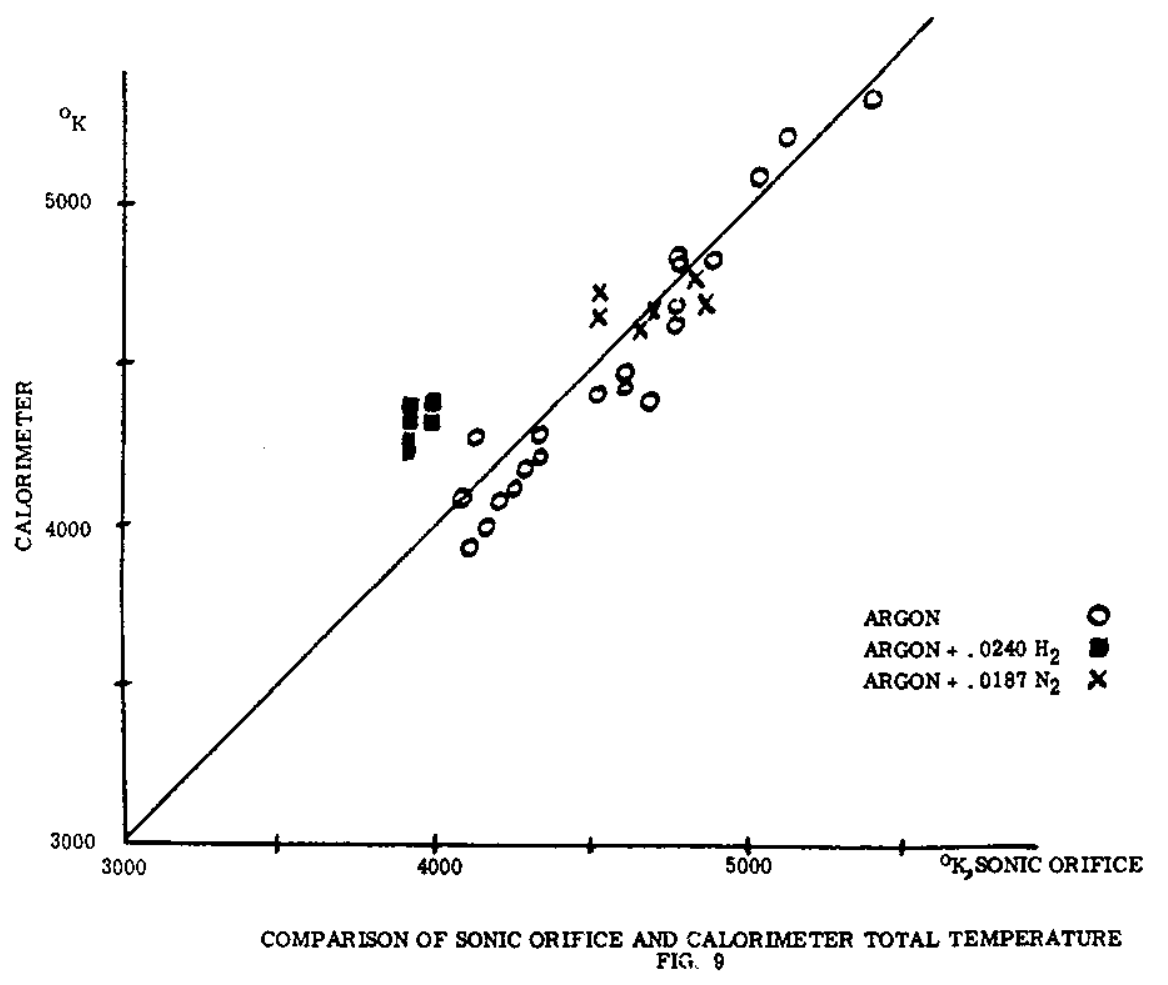
Fi. 9

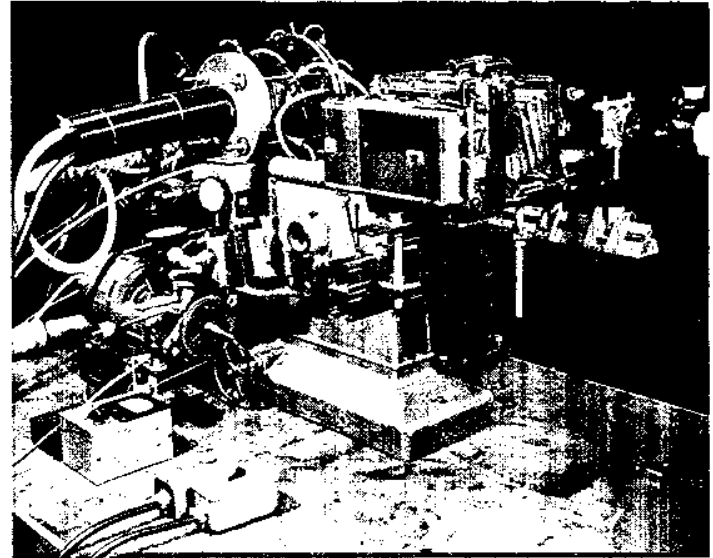

FIG. 8 REAR VIEW OF EXPERIMENTAL SETUP

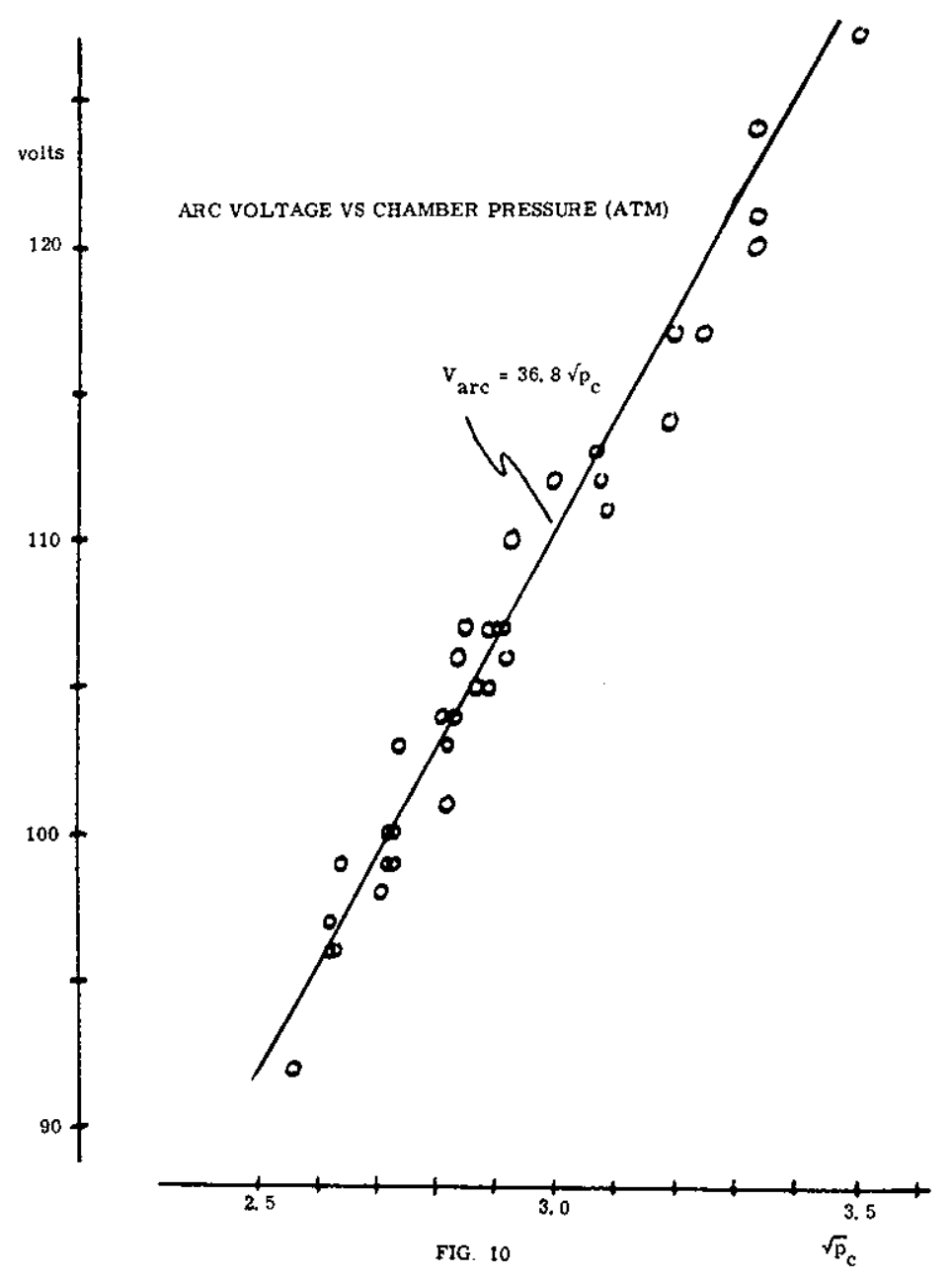



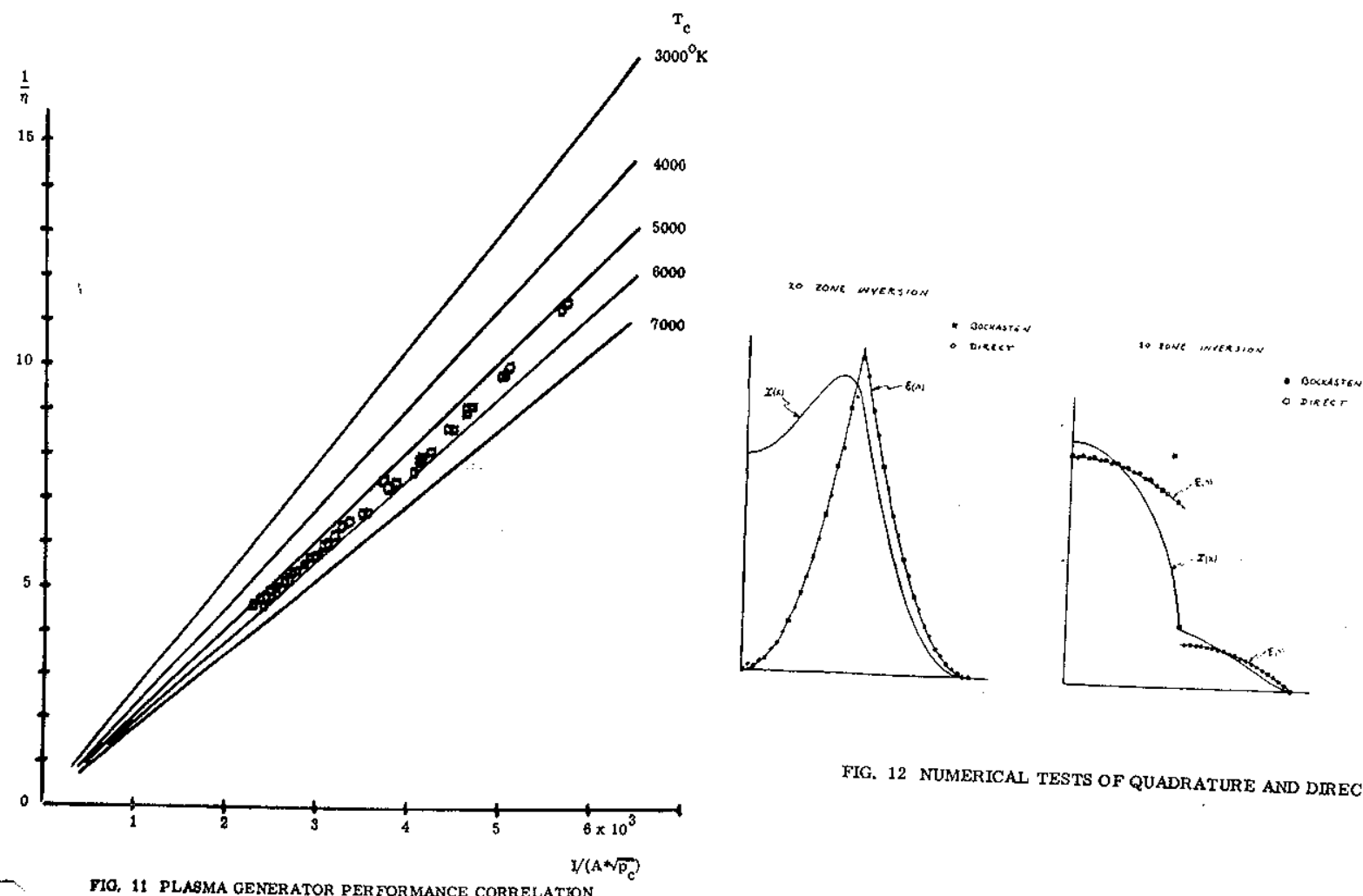

F10. I1 PLASMa generator PER FORMANCE CORRELATION
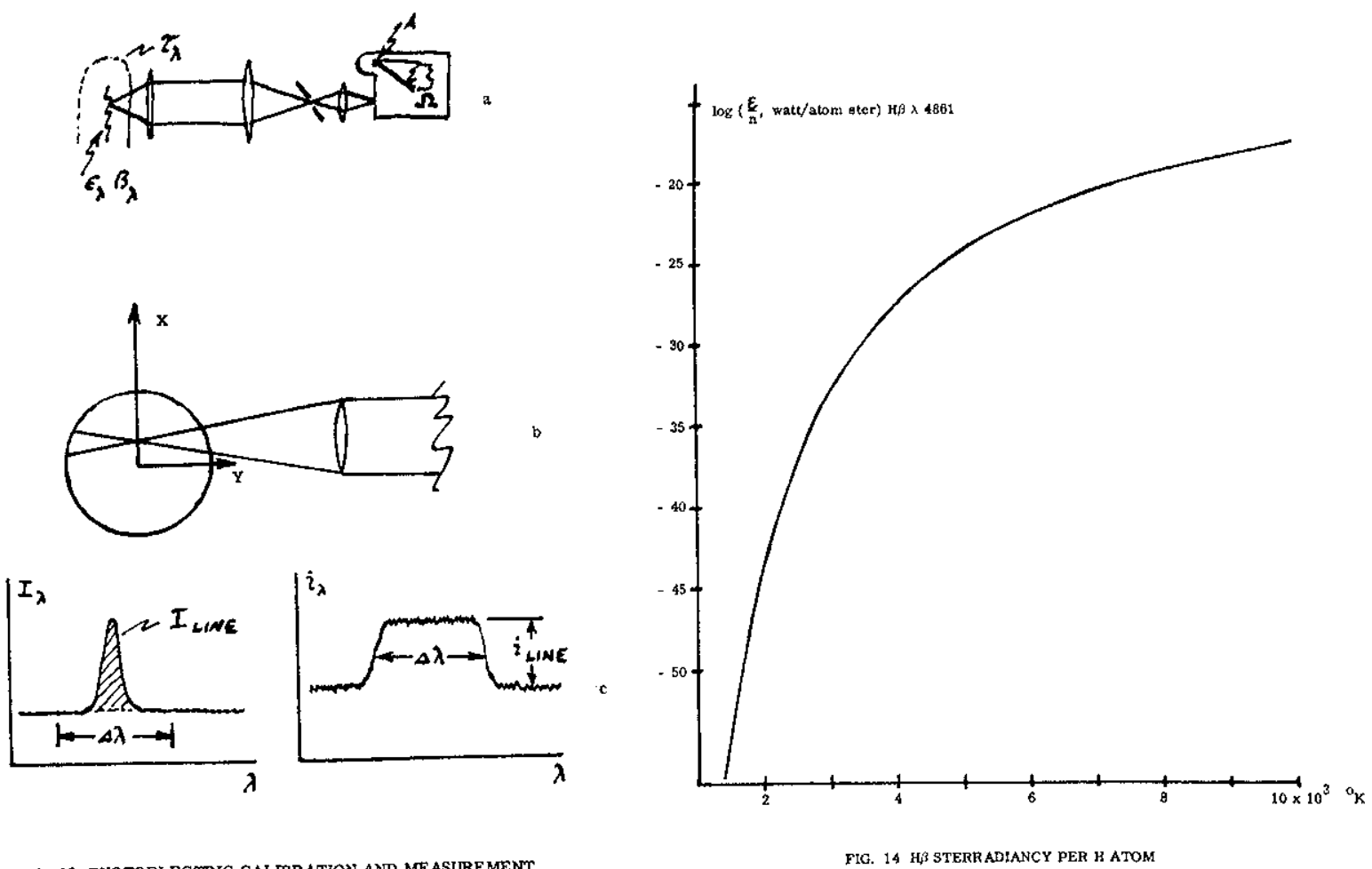

FIG. 13 PHOTOELECTRIC CALTERATION AND MEASUREMENT

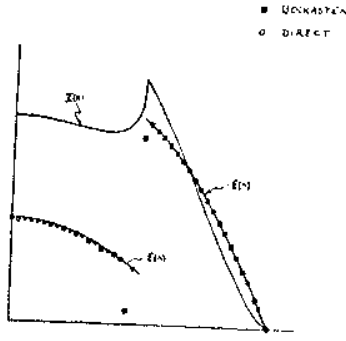

FIG. 12 NUMERICAL TESTS OF QUADRATURE AND DIRECT ABEL INVERSIONS 



FIG, I6 UNDEREXPANDED JET SPECTRA

a A alone, b A $+\mathrm{H}_{2}, \mathrm{cA}+\mathrm{N}_{2}$
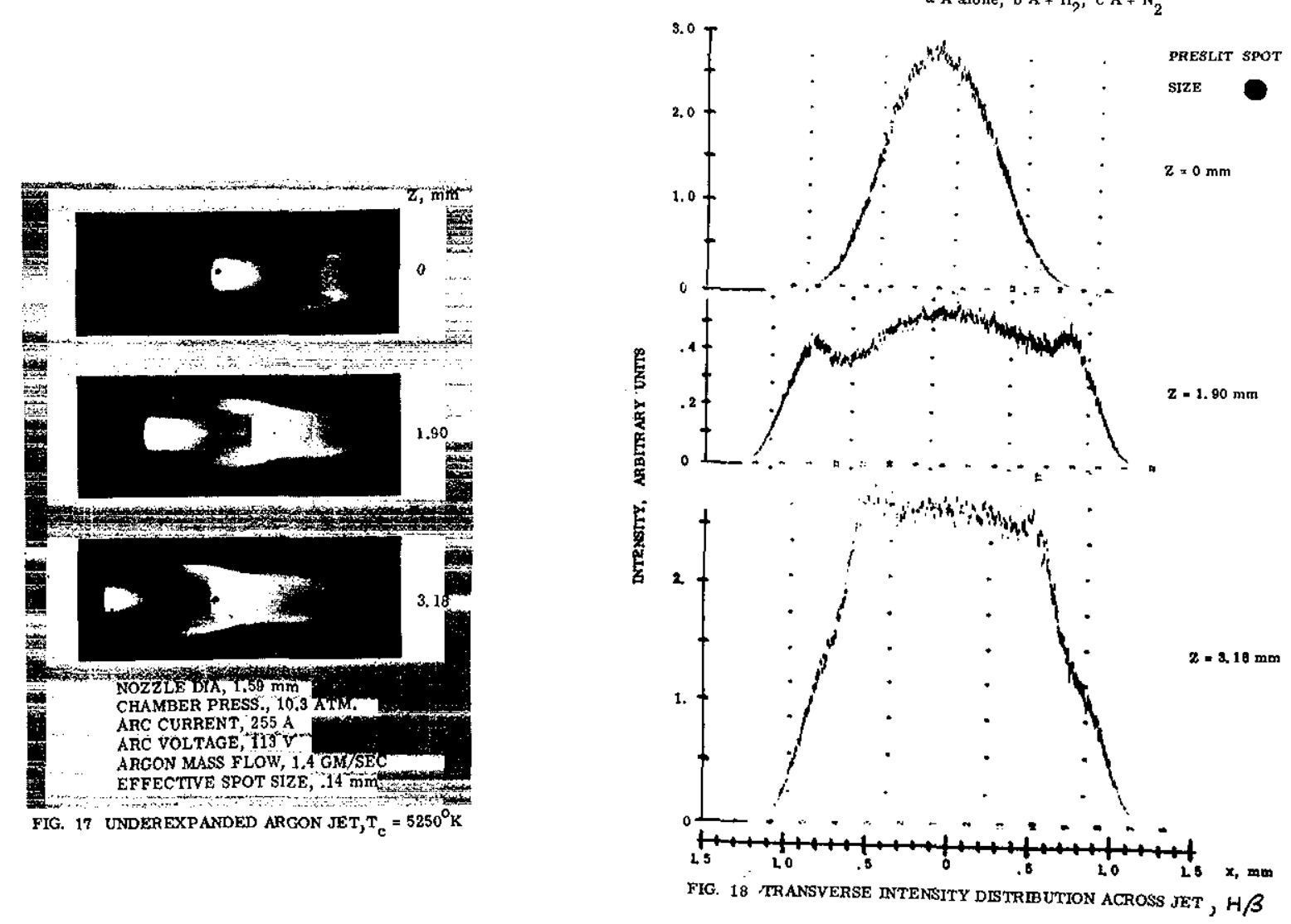
ว2

$y^{\prime} x$

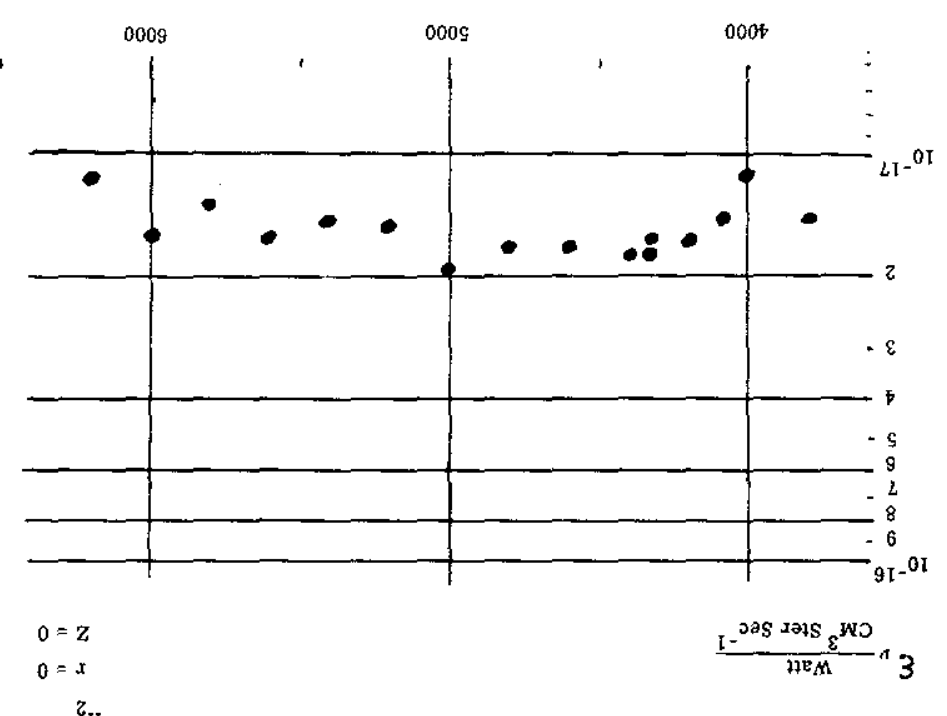

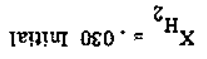

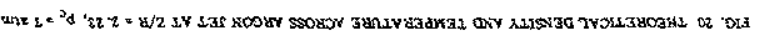

$\alpha / 2$

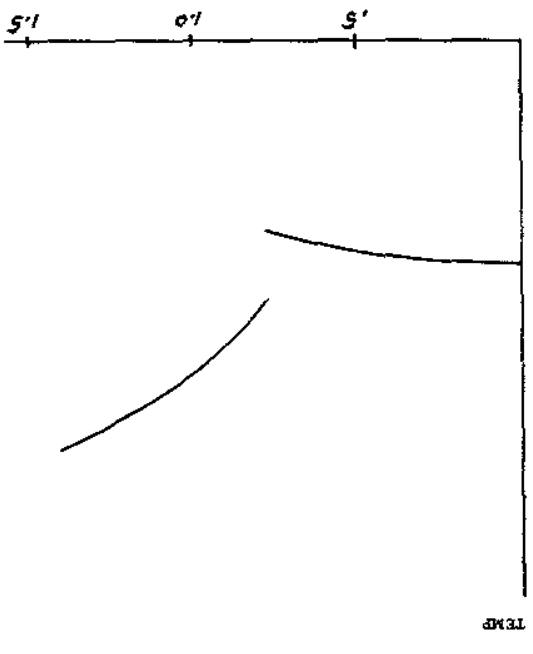

8/s/s:

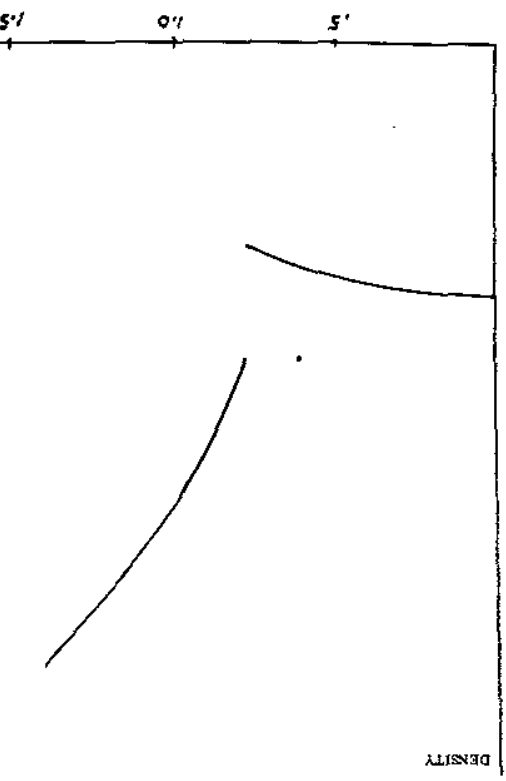

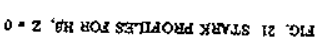

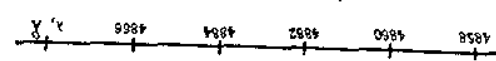

-

$\circ$

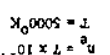

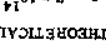

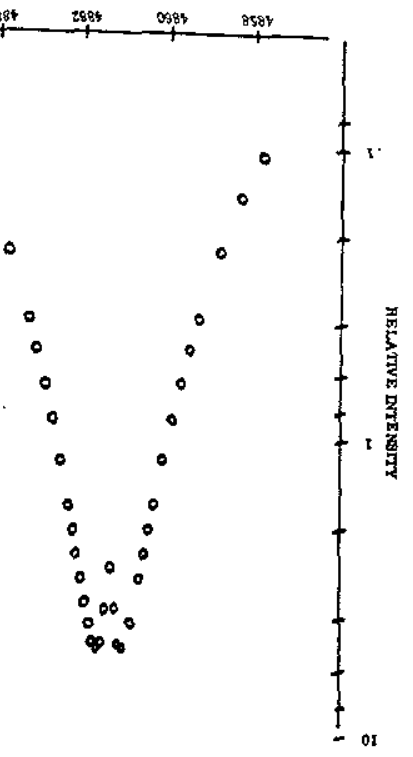

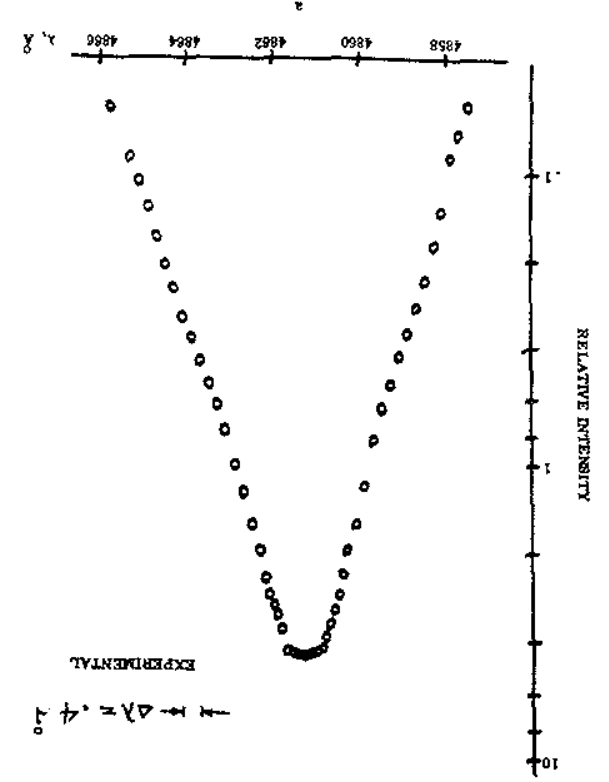

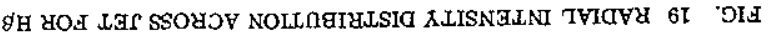

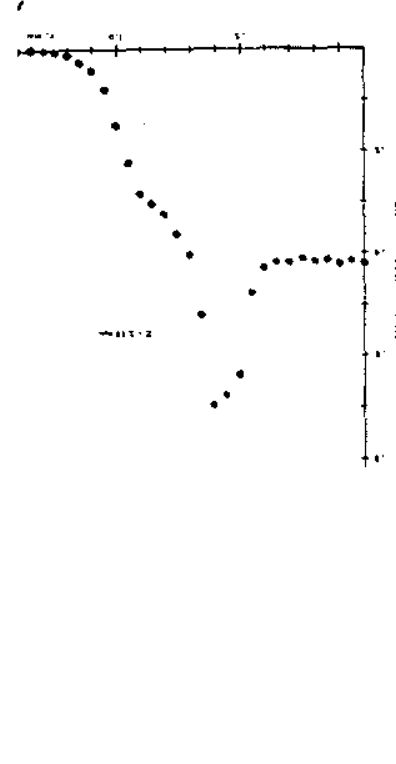

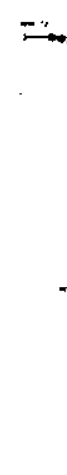

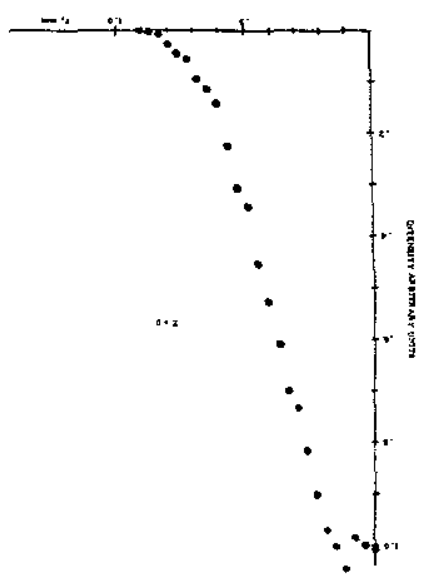




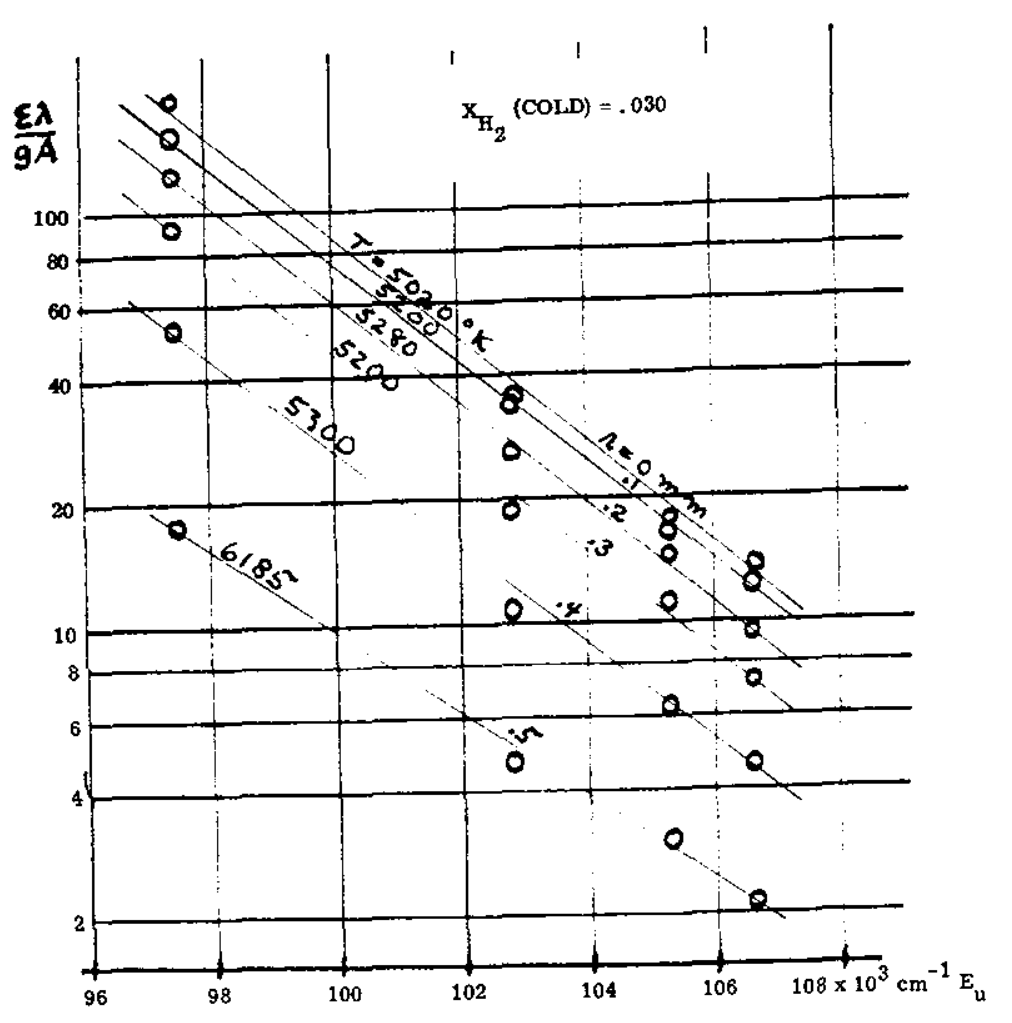

FIG. 23 BALMER SERIES TEMPERATURE DETER MINATION

ACROSS EXIT, $Z=0$

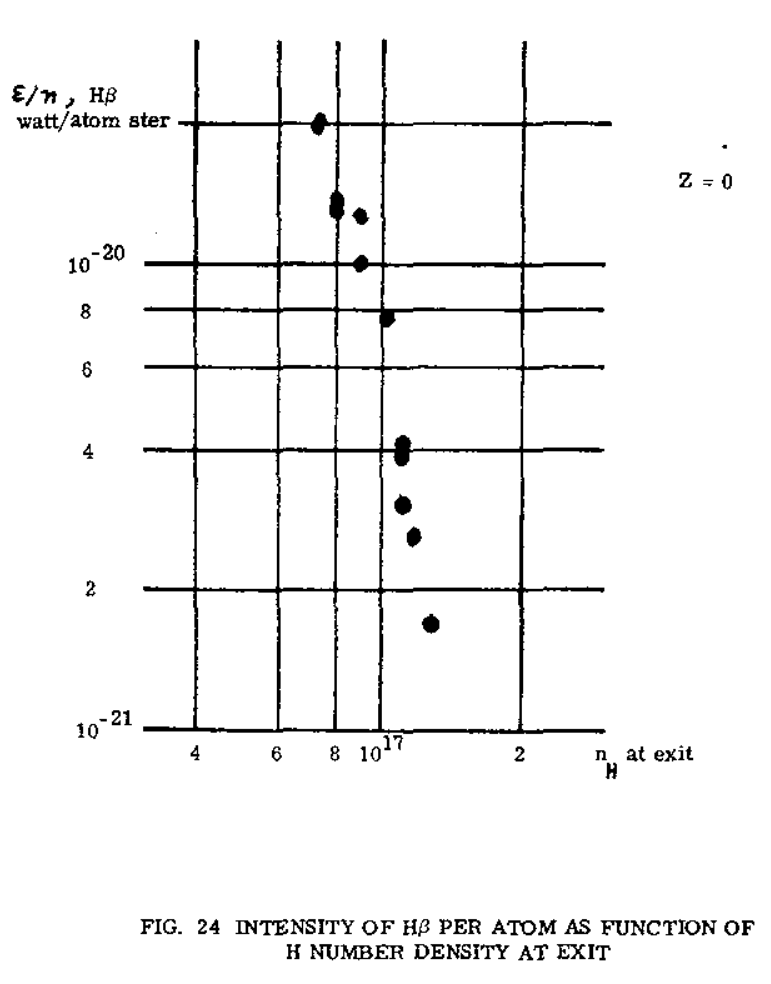

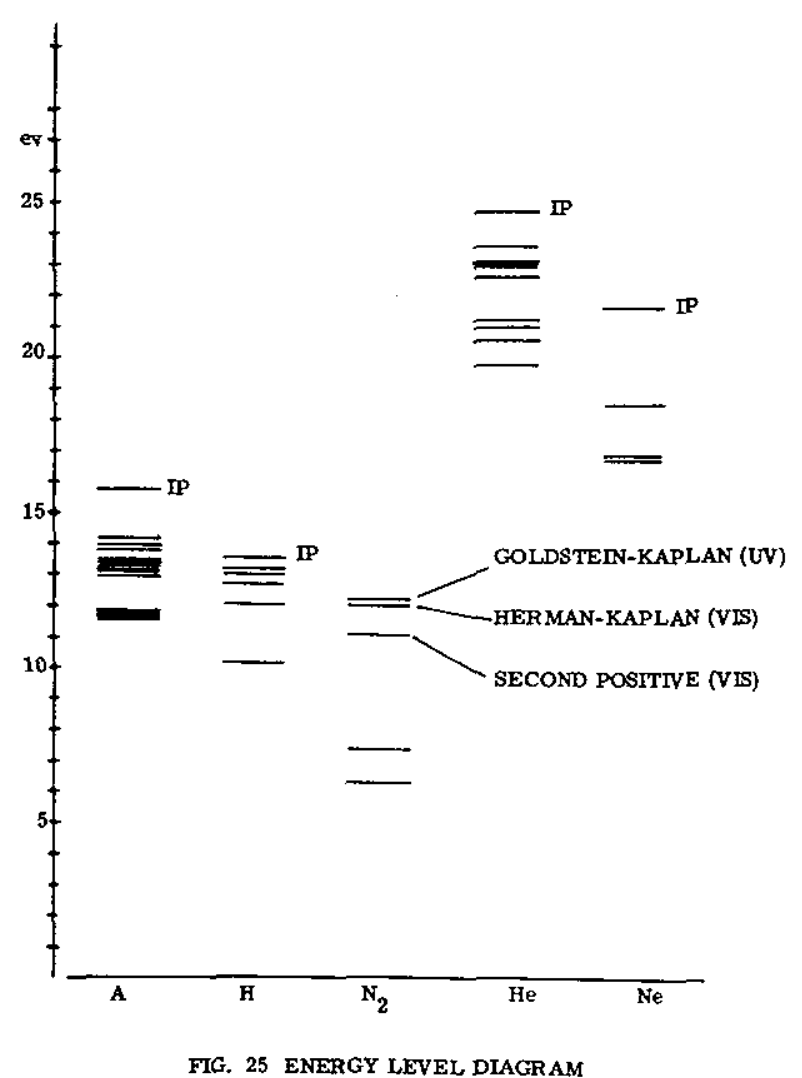

FIG. 25 ENERGY LEVEL DIAGRAM 